\title{
Prevalence, Trends, and Associated Risk Factors of Traumatic Dental Injury among Children and Adolescents in India: A Systematic Review and Meta-analysis
}

\author{
Sri Priya Narayanan ${ }^{1}$, Hemamalini Rath ${ }^{2}$, Abhijit Panda ${ }^{3}$, Shilpa Mahapatra ${ }^{4}$, Rubian H Kader ${ }^{5}$
}

\begin{abstract}
Aim and objective: Traumatic dental injury (TDI) is a significant public health concern. This study aimed to perform a systematic review on the prevalence, trends, and possible risk factors of dental trauma in permanent teeth among children and adolescents in India.

Materials and methods: Literature search was carried out, in PubMed, EMBASE, Web of Science, Cochrane, Google scholar, and Gray literature (MDS dissertation, manuscripts) database up to October 5, 2020, reporting on dental trauma prevalence in India. Meta-analyses were done using random effects model. Pooled estimates were calculated with a confidence interval of $95 \%(95 \% \mathrm{Cl})$ both for prevalence and odds ratios (OR). Trend analysis was performed for the included studies. Quality assessment of the included studies was done using the Hoy checklist for prevalence studies. Qualitative synthesis was done for predictors in which meta-analysis could not be performed.

Results: This online searching strategy collected and listed 2,491 articles on this topic. After evaluating their titles and abstracts, only 59 were finally selected for complete review and data collection. All studies had been performed in children and adolescents. The pooled prevalence of dental trauma in permanent teeth was $11 \%$. Positive summary association of dental trauma with male gender (pooled OR $=1.52 ; 95 \% \mathrm{Cl}$ : 1.37-1.70), inadequate lip coverage (pooled $\mathrm{OR}=4.76 ; 95 \% \mathrm{Cl}: 3.18-7.11$ ), and increased overjet of $>3.5 \mathrm{~mm}$ (pooled $\mathrm{OR}=4.84 ; 95 \% \mathrm{Cl}: 2.86-8.19$ ) and $>5.5 \mathrm{~mm}$ (pooled $\mathrm{OR}=4.93 ; 95 \% \mathrm{Cl}: 4.32-5.63$ ) was observed. Prevalence of dental trauma showed an increasing trend with time. All of the studies were having moderate-high risk of bias.

Conclusion: Approximately 9-13\% of the children and adolescents in India presented some type of TDI in permanent teeth, with an increasing trend. Boys, children, and adolescents presenting inadequate lip coverage, or an increased overjet greater than 3.5 and $5.5 \mathrm{~mm}$ are more likely to have traumatic dental injuries.

Clinical significance: Future population-based analytical studies on TDI in India are recommended.

Keywords: Adolescent, Children, Dental trauma, Inadequate lip coverage, Overjet, Permanent teeth, Systematic review.

The Journal of Contemporary Dental Practice (2021): 10.5005/jp-journals-10024-3212
\end{abstract}

\section{INTRODUCTION}

Traumatic dental injury (TDI) is a significant public health concern. It is presumed to be the fifth most prevalent dental disease in the world and around $20 \%$ of people suffer from trauma to teeth at some point in their life. A meta-analysis of the worldwide global burden of TDI reported a prevalence of $15.2 \%$ in permanent dentition alone. ${ }^{1}$ A 12-year review of literature stated that approximately two-thirds of all diagnosed TDIs occurred in children and adolescents. ${ }^{2}$ Various population-based studies have been conducted in different states of India to quantify TDI and the prevalence ranged from $2.05^{3}$ to $50 \% .{ }^{4}$ There has been an increase in the number of observational studies carried out on TDI over the past decade.

Previous studies have shown that, as a consequence of dental tissue trauma, bacterial invasion in the exposed dentinal tubules could lead to pulpal inflammation and subsequent necrosis, resulting in discoloration or sometimes even loss of the tooth. Undoubtedly, TDI can thus negatively affect the psychological development in children and adolescents. Moreover, the treatment is expensive and time-consuming. ${ }^{5}$

TDI is not a disease but a consequence of several unavoidable risk factors in life. ${ }^{6}$ Published literature has reported host factors like male gender, increased overjet, inadequate lip coverage, along with environmental factors, such as unsafe playgrounds, risk-taking behavior, and violence, to be mostly associated with TDI., ${ }^{1,6-12}$ Some studies have observed obesity and socioeconomic factors
${ }^{1-5}$ Department of Public Health Dentistry, SCB Dental College and Hospital, Cuttack, Odisha, India

Corresponding Author: Sri Priya Narayanan, Department of Public Health Dentistry, SCB Dental College and Hospital, Cuttack, Odisha, India, Phone: +91 9676365683/+91 8919737142, e-mail: dr.nsripriya@ gmail.com

How to cite this article: Narayanan SP, Rath H, Panda A, et al. Prevalence, Trends, and Associated Risk Factors of Traumatic Dental Injury among Children and Adolescents in India: A Systematic Review and Metaanalysis. J Contemp Dent Pract 2021;22(10):1206-1224.

Source of support: Nil

Conflict of interest: None

to be associated with higher incidence and prevalence of TDI in permanent teeth. ${ }^{10,13}$

A previous systematic review included studies for TDI in both primary and permanent dentition, before April 2019 in India. ${ }^{14}$ The review has concluded that there is high degree of variability followed by heterogeneity in the data from primary studies. Also, there is a lack of empirical evidence on the measures of trends over the years and other associated factors, such as obesity and socioeconomic status for TDI across urban and rural India. Such major gaps ultimately hinder careful planning, better decision-making, and the development of an effective intervention 
for the prevention and management of TDI. Therefore, the present systematic review and meta-analysis of published literature made an attempt to provide a precise pooled estimate by including a greater number of recent studies and comprehensive assessment of TDI prevalence in permanent dentition, trends, and reliable association of various risk factors among Indian children and adolescents.

\section{Materials and Methods}

\section{Study Design and Search Strategy}

The present systematic review and meta-analysis were undertaken in accordance with the guidelines of the COSMOS-E: Guidance on conducting systematic reviews and meta-analyses of observational studies of etiology. ${ }^{15}$ A comprehensive literature research of online databases, PubMed Medline, Web of Science, Cochrane Central, EMBASE, and Gray literature (MDS dissertation, manuscripts) from inception to October 5, 2020, was conducted. In addition to these electronic searches, the reference lists of key publications or further material were manually searched. Further articles were manually hand-searched from the citation list of the published literature. The studies from these databases were then imported to Mendeley reference manager software for the removal of duplicate titles.

\section{Keywords Included in the Search Strategy for all Six Databases (Title, Abstract, and MeSH Terms of Papers)} (Table 1)

(Prevalence OR incidence OR survey OR epidemiology OR "cross sectional" OR Etiology) AND (dental OR teeth OR tooth) AND (trauma OR injury OR fracture OR avulsion OR dislocation OR luxation) AND (child OR children OR adolescents OR young OR school) AND (India).

\section{Study Eligibility Criteria}

Population-based observational studies that evaluated the prevalence of TDI in permanent dentition were eligible. The results from conference proceedings, editorials, letters, reviews, and metaanalysis and publications with incomplete data which could not be obtained from the authors were not included. Studies pertaining to primary dentition as well as those reported from nonrepresentative population (athletes, visually impaired or special needs group, studies done exclusively on male and female population) were also excluded from the present meta-analysis.

\section{Study Selection and Data Collection Process}

Two independent reviewers (SPN and RHK) screened all the titles of retrieved records from the databases, followed by a screening of abstracts of relevant titles (Kappa score $=0.81$ ). Abstracts were selected if they fulfilled the selection criteria. Any disagreements about selection were discussed with a third reviewer (HR) for resolution. All duplicates were removed after verifying the most recent and complete version. Full-text studies were retrieved for the selected abstracts and additionally reference lists of these studies were searched. The retrieved full-text studies were assessed further to ensure they satisfied the inclusion criteria.

\section{Assessment of Quality in Included Studies}

After the full-text screening, all the articles were subjected to risk of bias assessment using a 10-item checklist adapted from Hoy et al. (2012). ${ }^{16}$ The selected articles were thus assessed for the representation of the population, sampling, random selection, nonresponse bias, data collected directly from subjects, case definition, reliability and validity of the method used, mode of data collection, and length of shortest prevalence period. Based on the assessment, studies were identified as high, moderate, or low risk.

\section{Data Collection and Extraction}

A data collection form was designed in Microsoft Excel to extract and enter the relevant data fields from the selected full-text studies. Data extraction was performed by the two reviewers independently and in duplicate. When needed, authors were contacted to gather missing information. The excel sheet was saved as a commaseparated-values (.csv) file. The data for each included study were then tabulated (Table 2).

\section{Statistical Analysis}

Statistical analysis for pooled prevalence and to obtain a forest plot to demonstrate the degree of heterogeneity among the selected articles was performed using $R$ (version 3.0.2) software after extracting data in an excel sheet. Subgroup analyses were further conducted to estimate and verify the influence of studies, by groups, on the pooled results.

Review Manager (Review Manager v. 5.3, The Cochrane Collaboration; Copenhagen, Denmark) was used to obtain forest plots and odds ratio (OR) for associated factors with TDI. The software uses Chi-square, $I^{2}$, and $\mathrm{Tau}^{2}$ to study heterogeneity. The

Table 1: Search strategy based on population, exposure, comparison, outcome, and study design (PECOS) criteria

\begin{tabular}{llll}
\hline Study design (AND) & TDI (AND) & Associated factors (AND) & Population (AND) \\
\hline Prevalence & Traumatized teeth & Etiology & School child \\
Cross-sectional study & Dentoalveolar trauma & Etiology & Child \\
Epidemiology & Oral trauma & Caus (cause, causation, & Adolescent \\
Survey & Traumatized incisors & causative factors) & Young \\
Point estimate & Permanent anterior & Malocclusion & Minor \\
Cohort analysis & Tooth trauma & Incisor overjet & Young child \\
Cross sectional analysis & Teeth trauma & Anterior overjet & School students \\
Observational analysis & Tooth fractures & Risk factors & School \\
Disease frequency & Teeth fractures & Associated factors & \\
Cohort Study & Teeth injuries & & \\
Cross-sectional studies & Tooth injuries & & \\
Epidemiologic study Incidence & Traumatic dental injuries & & \\
Longitudinal study & Dental trauma & & \\
Observational study & & & \\
Population study & & & \\
Prospective study & & & \\
Retrospective study & & & \\
\hline
\end{tabular}


Table 2: Details of categories under which data were extracted from the included studies

\begin{tabular}{|c|c|c|c|c|c|}
\hline Demographic details & Study methods & $\begin{array}{l}\text { TDI prevalence and } \\
\text { tooth type }\end{array}$ & Place of occurrence of TDI & Cause of TDI & Associated factors \\
\hline Author last name & Type of study & TDI number & Home & Fall & Gender \\
\hline Year of publication & $\begin{array}{l}\text { Calculated sample } \\
\text { size }\end{array}$ & TDI percentage & Street & Violence & Lip competency \\
\hline Region of the study & $\begin{array}{l}\text { Total sample size } \\
\text { taken }\end{array}$ & $\begin{array}{l}\text { Tooth type affected: } \\
\text { Number and } \\
\text { percentages }\end{array}$ & Playground & Collision & Overjet \\
\hline $\begin{array}{l}\text { State where the study } \\
\text { was conducted }\end{array}$ & Sampling strategy & $\begin{array}{l}\text { Type of Trauma-based } \\
\text { on the classification }\end{array}$ & School & Biting hard & BMI \\
\hline \multirow[t]{3}{*}{$\begin{array}{l}\text { Journal in which it was } \\
\text { published }\end{array}$} & Evaluation period & & $\begin{array}{l}\text { School type (Government } \\
\text { school/Private school) }\end{array}$ & $\begin{array}{l}\text { Road traffic } \\
\text { accidents }\end{array}$ & Molar relation \\
\hline & Age-group & & & Sports & Urban/Rural region \\
\hline & TDI classification & & & $\begin{array}{l}\text { Cannot remember } \\
\text { and others }\end{array}$ & $\begin{array}{l}\text { Socioeconomic } \\
\text { status }\end{array}$ \\
\hline
\end{tabular}

Flowchart 1: Flow diagram of literature search according to PRISMA statement

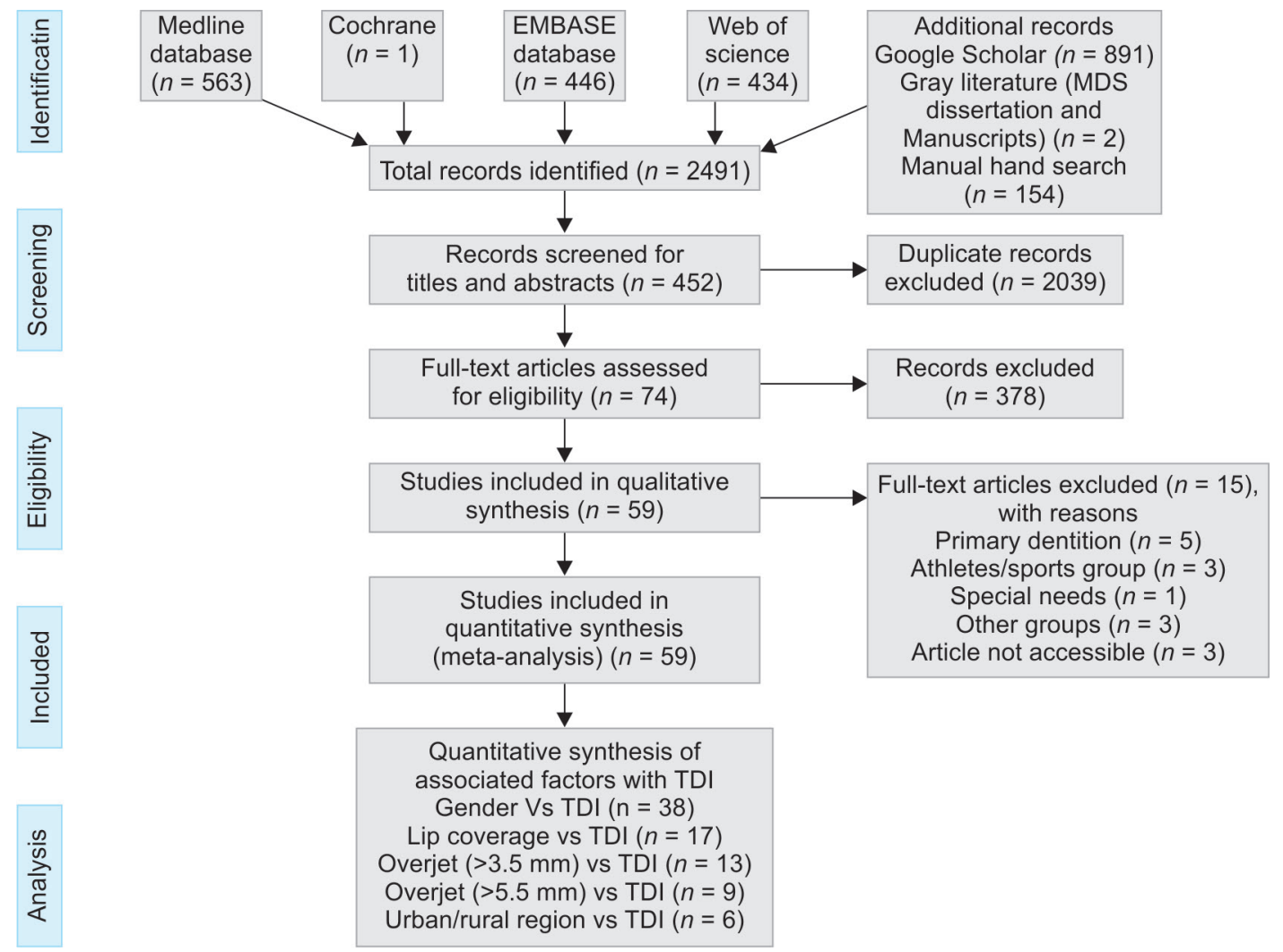

$p$-value was set at $<0.05$ for the results to be significant. Metaanalysis was performed by using a random effects model due to the variation between the studies.

Trend analysis was done in Microsoft Excel. The Statistical analysis for the given dataset was performed using the "Data analysis toolpak" toolbox from Excel in the "Data" section.

\section{Results}

\section{Study Selection}

Flowchart 1 shows a flowchart outlining the number of articles identified at each step of the literature search. The searches resulted in 2,491 references in total. The articles were checked for duplicates using the Mendeley reference manager and 2,039 references were excluded in the process. The titles and abstracts of 452 studies were then screened against the inclusion criteria, independently and in duplicate, discarding 378 studies. Additionally, 15 more studies were excluded after quality assessment. Therefore, 59 records met the inclusion criteria for this review.

\section{Study Characteristics}

A total of 59 studies ( 58 cross-sectional studies and 1 case-control study) were included in the final analysis. A total of 162,997 participants provided data for the included studies. All the included 
studies involved the children and adolescent population. The study characteristics extracted from the included observational studies are described in Table 3.

\section{Quality Assessment}

The risk of bias assessment was carried out using the Hoy et al. scale for 59 studies, out of which $47 \%$ were at moderate risk and the remaining $53 \%$ were at high risk of bias. Low scores were mainly due to lack of representativeness of the sample and proper definition or criteria for TDI. Furthermore, the adjusted odds ratio for associated factors has not been reported adequately. Scores for individual studies are mentioned in Table 4.

\section{Pooled Prevalence of TDI in Permanent Teeth in India}

The result of the meta-analysis for pooling the proportion of TDI is graphically represented in Figure 1A. Forest plot of meta-analysis of

Table 3: Study characteristics of the included studies

\begin{tabular}{|c|c|c|c|c|c|c|c|c|}
\hline Author & Year & Region & State & Age & $\begin{array}{l}\text { Sample } \\
\text { size }\end{array}$ & $\begin{array}{l}\text { Study } \\
\text { design }\end{array}$ & Sampling strategy & Classification \\
\hline Gauba $^{17}$ & 1967 & NA & NA & NA & 4,296 & CS & NA & NA \\
\hline Rai and Munshi ${ }^{18}$ & 1998 & South Kanara & Karnataka & NA & 4,500 & CS & NA & NA \\
\hline Gupta et al. ${ }^{19}$ & 2002 & South Kanara & Karnataka & $8-14$ & 2,100 & CS & Random sampling & $\begin{array}{c}\text { Hargreaves and } \\
\text { Craig }\end{array}$ \\
\hline Jose and Joseph ${ }^{20}$ & 2003 & Vadavucode & Kerala & $12-15$ & 1,068 & CS & NA & $\begin{array}{c}\text { Clinical } \\
\text { examination }\end{array}$ \\
\hline Tangade $^{21}$ & 2007 & Belgaum & Karnataka & $12-15$ & 3,621 & CS & $\begin{array}{l}\text { Simple random } \\
\text { sampling }\end{array}$ & WHO \\
\hline David et al. ${ }^{22}$ & 2009 & Trivandrum & Kerala & 12 & 838 & CS & $\begin{array}{l}\text { Stratified two stage } \\
\text { random cluster } \\
\text { sampling }\end{array}$ & O'Brien \\
\hline Bharadwaj $^{23}$ & 2009 & Coorg & Karnataka & $7-15$ & 4,036 & CS & $\begin{array}{l}\text { Stratified random } \\
\text { sampling }\end{array}$ & Garcia Godoy \\
\hline Ravishankar et al. ${ }^{24}$ & 2010 & Davangere & Karnataka & 12 & 1,020 & CS & $\begin{array}{l}\text { Random } \\
\text { sampling }\end{array}$ & WHO \\
\hline Gupta et al. ${ }^{25}$ & 2010 & Baddi-barotiwala & $\begin{array}{l}\text { Himachal } \\
\text { Pradesh }\end{array}$ & $4-15$ & 1,059 & CS & $\begin{array}{l}\text { Simple random } \\
\text { sampling }\end{array}$ & $\begin{array}{c}\text { Modified Ellis ano } \\
\text { Davies }\end{array}$ \\
\hline Ingle et al. ${ }^{26}$ & 2010 & Chennai & Tamil Nadu & $11-13$ & 687 & CS & $\begin{array}{l}\text { Random } \\
\text { sampling }\end{array}$ & Ellis and Davies \\
\hline Kumar et al. ${ }^{27}$ & 2011 & Ambala & Haryana & NA & 963 & CS & NA & NA \\
\hline Naveen et al. ${ }^{28}$ & 2011 & Tandoor & Andhra Pradesh & 12 & 1,020 & CS & NA & WHO \\
\hline Patel and Sujan 29 & 2012 & Vadodara & Gujarat & $8-13$ & 3,708 & CS & $\begin{array}{c}\text { Multistage sampling } \\
\text { technique }\end{array}$ & Andreason \\
\hline Govindarajan et al. ${ }^{30}$ & 2012 & Chidambaram & Tamil Nadu & $3-13$ & 3,200 & CS & $\begin{array}{l}\text { Simple random } \\
\text { sampling }\end{array}$ & Ellis and Davies \\
\hline Ankola et al. ${ }^{31}$ & 2012 & Belgaum & Karnataka & $6-11$ & 13,200 & CS & Random sampling & WHO \\
\hline Sharma and Dua ${ }^{32}$ & 2012 & Dera bassi & Punjab & $7-12$ & 880 & CS & NA & Ellis and Davies \\
\hline Rajesh et al. ${ }^{33}$ & 2012 & 4 states & South India & $4-16$ & 30,000 & CS & $\begin{array}{l}\text { Multistage cluster } \\
\text { sampling }\end{array}$ & $\begin{array}{c}\text { Modified Ellis anc } \\
\text { Davies }\end{array}$ \\
\hline Dhingra et al. ${ }^{34}$ & 2012 & Faridabad & Haryana & $12-15$ & 1,090 & CS & Multistage sampling & Ellis and Davies \\
\hline Vijaykumar et al. ${ }^{35}$ & 2013 & Bengaluru & Karnataka & $10-12$ & 858 & CS & $\begin{array}{l}\text { Simple random } \\
\text { sampling }\end{array}$ & $\begin{array}{c}\text { Clinical } \\
\text { examination }\end{array}$ \\
\hline Basavaraj et al. ${ }^{36}$ & 2013 & Modinagar & Uttar Pradesh & $12-15$ & 900 & CS & $\begin{array}{l}\text { Two stage cluster } \\
\text { sampling }\end{array}$ & WHO \\
\hline Chopra et al. ${ }^{37}$ & 2014 & Panchkula & Haryana & $12-15$ & 810 & CS & $\begin{array}{l}\text { Multi stage sampling } \\
\text { technique }\end{array}$ & Ellis mod Holland \\
\hline Bansode et al. ${ }^{38}$ & 2014 & Aurangabad & Maharashtra & $>10$ & 1,000 & CS & NA & NA \\
\hline Krishna murthy et al. ${ }^{39}$ & 2014 & Bengaluru & Karnataka & $5-16$ & 2,132 & CS & $\begin{array}{l}\text { Multistage random } \\
\text { sampling }\end{array}$ & Ellis and Davies \\
\hline Prasad et al. ${ }^{40}$ & 2014 & Gurgaon & Haryana & $12-15$ & 671 & CS & $\begin{array}{c}\text { Multistage sampling } \\
\text { technique }\end{array}$ & Ellis and Davies \\
\hline Chandra $^{41}$ & 2014 & Greater Noida & New Delhi & NA & 9,074 & CS & NA & NA \\
\hline Vashisth et al. ${ }^{42}$ & 2014 & Kangra & $\begin{array}{l}\text { Himachal } \\
\text { Pradesh }\end{array}$ & $11-14$ & 1,041 & CS & NA & $\begin{array}{c}\text { Modified Ellis anc } \\
\text { Davies }\end{array}$ \\
\hline
\end{tabular}


Table 3: (Contd...)

\begin{tabular}{|c|c|c|c|c|c|c|c|c|}
\hline Author & Year & Region & State & Age & $\begin{array}{l}\text { Sample } \\
\text { size }\end{array}$ & $\begin{array}{l}\text { Study } \\
\text { design }\end{array}$ & Sampling strategy & Classification \\
\hline Gojanur et al. $^{3}$ & 2015 & Mathura & Uttar Pradesh & $5-8$ & 1,657 & CS & $\begin{array}{l}\text { Stratified cluster } \\
\text { random sampling }\end{array}$ & Ellis and Davies \\
\hline Mathur et al. ${ }^{13}$ & 2015 & $\mathrm{NCT}$ & New Delhi & $12-15$ & 1,386 & CS & $\begin{array}{l}\text { Multistage sampling } \\
\text { technique }\end{array}$ & Modified O'Brien \\
\hline Basha et al. ${ }^{43}$ & 2015 & Davangere & Karnataka & $6-13$ & 1,550 & $\begin{array}{l}\text { Nested } \\
\text { CS }\end{array}$ & NA & Andreason \\
\hline Hegde and Sajnani ${ }^{44}$ & 2015 & Mangaluru & Karnataka & $14-70$ & 2,000 & CS & NA & WHO \\
\hline Kirthiga et al. ${ }^{45}$ & 2015 & Davangere & Karnataka & $11-16$ & 2,000 & CS & $\begin{array}{c}\text { Two stage random } \\
\text { sampling }\end{array}$ & Ellis and Davies \\
\hline $\begin{array}{l}\text { Ramaiah and } \\
\text { Maraiah }^{46}\end{array}$ & 2015 & Shivamoga & Karnataka & $9-14$ & 1,450 & CS & Random sampling & WHO \\
\hline Singh et al. ${ }^{47}$ & 2015 & Lucknow & Uttar Pradesh & $3-17$ & 1,112 & CS & NA & Ellis and Davies \\
\hline Yadav et al. ${ }^{4}$ & 2015 & Bhopal & Madhya Pradesh & $12-15$ & 200 & CS & Snowball sampling & NA \\
\hline Ain et al. ${ }^{48}$ & 2016 & NA & Kashmir & 12 & 1,600 & CS & $\begin{array}{l}\text { Multistage sampling } \\
\text { technique }\end{array}$ & Ellis and Davies \\
\hline Gupta et al. ${ }^{49}$ & 2016 & Bhopal & Madhya Pradesh & $11-15$ & 1,518 & CS & $\begin{array}{l}\text { Stratified cluster } \\
\text { sampling }\end{array}$ & $\begin{array}{l}\text { Andreason and } \\
\text { WHO codes }\end{array}$ \\
\hline Prasad et al. ${ }^{50}$ & 2016 & West Godavari & Andhra Pradesh & NA & 5,203 & CS & $\begin{array}{l}\text { Simple random } \\
\text { sampling }\end{array}$ & NA \\
\hline $\begin{array}{l}\text { Hegde and } \\
\text { Agrawal }^{51}\end{array}$ & 2017 & Kharagpur-Belapur & Navi Mumbai & $9-14$ & 3,012 & CS & $\begin{array}{l}\text { Stratified random } \\
\text { sampling }\end{array}$ & Andreason \\
\hline Garg et al. ${ }^{52}$ & 2017 & NA & Delhi & $7-14$ & 3,000 & CS & $\begin{array}{l}\text { Multistage random } \\
\text { sampling }\end{array}$ & $\begin{array}{l}\text { Andreason and } \\
\text { WHO }\end{array}$ \\
\hline Goyal et al. ${ }^{53}$ & 2017 & Dhanganagar & Rajasthan & $10-17$ & 3,002 & $\begin{array}{l}\text { case } \\
\text { control }\end{array}$ & $\begin{array}{l}\text { Multistage sampling } \\
\text { technique }\end{array}$ & Ellis and Davies \\
\hline Shashikiran et al. ${ }^{54}$ & 2017 & Bhopal & Madhya Pradesh & $6-12$ & 1,204 & $\mathrm{CS}$ & Random sampling & WHO \\
\hline Sharva et al. ${ }^{55}$ & 2017 & Bhopal & Madhya Pradesh & $12-15$ & 1,100 & CS & Three stage sampling & WHO \\
\hline $\begin{array}{l}\text { Shah and } \\
\text { Jeevanandan } \\
56\end{array}$ & 2018 & Chennai & Tamil Nadu & $6-15$ & 108 & CS & NA & $\begin{array}{c}\text { Clinical } \\
\text { examination }\end{array}$ \\
\hline Khandelwal et al. ${ }^{57}$ & 2018 & Indore & Madhya Pradesh & $3-17$ & 5,000 & CS & Random sampling & Ellis and Davies \\
\hline $\begin{array}{l}\text { Saraswathi and } \\
\text { Kumar Rathinavelu }\end{array}$ & 2018 & Rohtak & Haryana & 12 & 2,000 & CS & NA & Ellis and Davies \\
\hline Juneja et al. ${ }^{59}$ & 2018 & Indore & Madhya Pradesh & $8-15$ & 4,000 & CS & $\begin{array}{l}\text { Multistage random } \\
\text { sampling }\end{array}$ & $\begin{array}{c}\text { Modified Ellis and } \\
\text { Davies }\end{array}$ \\
\hline Bhagat and Singh ${ }^{60}$ & 2018 & Ghaziabad & Uttar Pradesh & $12-19$ & 1,819 & CS & NA & WHO \\
\hline Gupta et al. ${ }^{61}$ & 2018 & Jabalpur & Madhya Pradesh & $6-15$ & 2,671 & CS & $\begin{array}{l}\text { Stratified cluster } \\
\text { sampling }\end{array}$ & WHO \\
\hline Peter and Narayan ${ }^{62}$ & 2018 & Kottayam & Kerala & $15-18$ & 930 & CS & Multistage sampling & WHO \\
\hline Dharmani et al. ${ }^{63}$ & 2019 & Patiala & Punjab & $8-12$ & 3,000 & CS & $\begin{array}{l}\text { Simple random } \\
\text { sampling }\end{array}$ & Ellis and Davies \\
\hline Priyadarshini et al. ${ }^{64}$ & 2019 & Chennai & Tamil Nadu & $11-13$ & 825 & CS & $\begin{array}{l}\text { Simple random } \\
\text { sampling }\end{array}$ & Ellis and Davies \\
\hline Prasanna et al. ${ }^{65}$ & 2019 & Bengaluru & Karnataka & $7-14$ & 3,363 & CS & $\begin{array}{l}\text { Simple random } \\
\text { sampling }\end{array}$ & WHOTDI \\
\hline Nagarajappa et al. ${ }^{66}$ & 2019 & Kanpur & Uttar Pradesh & $12-15$ & 1,100 & CS & $\begin{array}{l}\text { Two stage stratified } \\
\text { random sampling }\end{array}$ & Ellis and Davies \\
\hline Das et al. ${ }^{67}$ & 2019 & Lucknow & Uttar Pradesh & $5-16$ & 500 & CS & $\begin{array}{l}\text { Simple random } \\
\text { sampling }\end{array}$ & $\begin{array}{c}\text { Clinical } \\
\text { examination }\end{array}$ \\
\hline Prakash and Kumari ${ }^{68}$ & 2019 & Patna & Bihar & $7-14$ & 2,820 & CS & NA & WHO \\
\hline $\begin{array}{l}\text { Shakuntala and } \\
\text { Kalpavriksha }{ }^{69}\end{array}$ & 2019 & Bengaluru & Karnataka & $9-14$ & 500 & CS & $\begin{array}{l}\text { Simple random } \\
\text { sampling }\end{array}$ & $\begin{array}{l}\text { Andreason with } \\
\text { WHO }\end{array}$ \\
\hline Ramachandran et al. ${ }^{70}$ & 2019 & Chettinad & Tamil Nadu & $20-73$ & 1,562 & CS & NA & WHO \\
\hline Basak et al. $^{71}$ & 2020 & Siliguri & West Bengal & $0-14$ & 780 & CS & Cluster sampling & WHO \\
\hline Lakshmi et al. $^{72}$ & 2020 & Chennai & Tamil Nadu & $8-15$ & 7,247 & CS & $\begin{array}{l}\text { Stratified random } \\
\text { sampling }\end{array}$ & Ellis and Davies \\
\hline
\end{tabular}


Table 4: Ascertainment of risk of bias in the included studies according to Hoy checklist

\begin{tabular}{|c|c|}
\hline Author & $\begin{array}{l}\text { Risk of bias } \\
\text { score }\end{array}$ \\
\hline Gojanur et al. $^{3}$ & 6 \\
\hline Yadav et al. ${ }^{4}$ & 7 \\
\hline Mathur et al. ${ }^{13}$ & 5 \\
\hline Ramachandran et al. ${ }^{70}$ & 7 \\
\hline Prakash and Kumari ${ }^{68}$ & 7 \\
\hline Das et al. ${ }^{67}$ & 7 \\
\hline Tangade $^{21}$ & 6 \\
\hline Khandelwal et al. ${ }^{57}$ & 5 \\
\hline Garg et al. ${ }^{52}$ & 7 \\
\hline Gupta et al. ${ }^{49}$ & 6 \\
\hline Prasad et al. ${ }^{40}$ & 7 \\
\hline Chopra et al. ${ }^{37}$ & 6 \\
\hline Basak et al. $^{71}$ & 6 \\
\hline Patel and Sujan ${ }^{29}$ & 6 \\
\hline Krishna Murthy et al. ${ }^{39}$ & 7 \\
\hline Ravishankar et al. ${ }^{24}$ & 6 \\
\hline Lakshmi et al. $^{72}$ & 6 \\
\hline Gupta et al. ${ }^{19}$ & 6 \\
\hline Sharma and Dua ${ }^{32}$ & 8 \\
\hline Nagarajappa et al. ${ }^{66}$ & 7 \\
\hline Juneja et al. ${ }^{59}$ & 6 \\
\hline Shashikiran et al. ${ }^{54}$ & 8 \\
\hline Bharadwaj $^{23}$ & 7 \\
\hline Peter and Narayan ${ }^{62}$ & 7 \\
\hline Basavaraj et al. ${ }^{36}$ & 7 \\
\hline Sharva et al. ${ }^{55}$ & 6 \\
\hline Priyadarshini et al. ${ }^{64}$ & 7 \\
\hline Dhingra et al. ${ }^{34}$ & 6 \\
\hline Gupta et al. ${ }^{61}$ & 7 \\
\hline Kirthiga et al. ${ }^{45}$ & 7 \\
\hline Dharmani et al. ${ }^{63}$ & 6 \\
\hline Basha et al. ${ }^{43}$ & 6 \\
\hline Govindarajan et al. ${ }^{30}$ & 8 \\
\hline Hegde and Agrawal ${ }^{51}$ & 6 \\
\hline Ain et al. ${ }^{48}$ & 6 \\
\hline Goyal et al. ${ }^{73}$ & 7 \\
\hline $\begin{array}{l}\text { Saraswathi and } \\
\text { Kumar Rathinavelu } 58\end{array}$ & 7 \\
\hline Ankola et al. ${ }^{31}$ & 6 \\
\hline Gupta et al. ${ }^{25}$ & 6 \\
\hline Ramaiah and Maraiah ${ }^{46}$ & 7 \\
\hline $\begin{array}{l}\text { Shakuntala and } \\
\text { Kalpavriksha }\end{array}$ & 7 \\
\hline Anegundi et al. ${ }^{60}$ & 6 \\
\hline Bhagat and Singh ${ }^{60}$ & 6 \\
\hline Singh et al. ${ }^{47}$ & 7 \\
\hline David et al. ${ }^{22}$ & 6 \\
\hline Vijaykumar et al. ${ }^{35}$ & 6 \\
\hline Prasanna et al. ${ }^{74}$ & 6 \\
\hline
\end{tabular}

\begin{tabular}{ll} 
Hegde and Sajnani $^{44}$ & 7 \\
Shah and Jeevanandan $^{56}$ & 6 \\
Gauba $^{17}$ & 8 \\
Rai and Munshi $^{18}$ & 8 \\
Jose and Joseph $^{20}$ & 7 \\
Ingle et al. $^{26}$ & 6 \\
Kumar et al. $^{27}$ & 7 \\
Naveen et al. $^{28}$ & 8 \\
Bansode et al. $^{38}$ & 6 \\
Chandra $^{41}$ & 8 \\
Vashisth et al. $^{42}$ & 7 \\
Prasad et al. & \\
\hline
\end{tabular}

studies in the prevalence of traumatic dental injuries in permanent teeth (all studies included $n=59$ ) revealed a pooled prevalence of $11 \%$ with $95 \% \mathrm{Cl}$ of $9-13 \%$ using random effect model.

\section{Sensitivity Analysis for the Pooled Prevalence of TDI in Permanent Teeth in India}

The result of the meta-analysis for pooling the proportion of TDI by removal of outlier studies ${ }^{4,67,68,70}$ on visual inspection of the forest plot is graphically represented in Figure 1B. No significant change in the heterogeneity was observed after excluding four outlier studies.

\section{Subgroup Analysis}

Subgroup analysis was performed based on various study level covariates contributing to clinical and methodological heterogeneity. Probable covariates were identified before analysis. The subgroup analysis was conducted by the state where the study was carried out as well as by the criteria used to classify TDI.

- Subgroup analysis based on the state where the study was conducted: Figure 2A depicts subgroup analysis by state with Karnataka subgroup including 14 studies and non-Karnataka including 45 studies. The forest plot revealed a nonsignificant effect of the moderator using mixed model analysis (random effects model within subgroups and fixed effects model between subgroups) suggesting that the study state does not modify the prevalence of TDI.

- Subgroup analysis based on the criteria used to classify TDI: Subgroup analysis by criteria used to classify TDI has been projected in Figure 2B. The forest plot revealed a nonsignificant effect of the moderator using mixed model analysis (random effects model within subgroups and fixed effects model between subgroups) implying that classification does not modify the prevalence of TDI.

\section{Meta-regression of the Study Level Covariates}

Among the study level covariates considered for meta-regression, both sample size and year of publication significantly explain the percentage of heterogeneity variation (18.15 and $4.89 \%$ ) found on the prevalence proportion (Table 5).

\section{Predictors}

\section{Association between Gender and TDI in Permanent Teeth}

Figure $3 \mathrm{~A}$ is a forest plot of 38 studies reporting the association between gender and traumatic dental injuries in permanent teeth. The study-specific odds ratio was 1.52 and summary effect estimates 


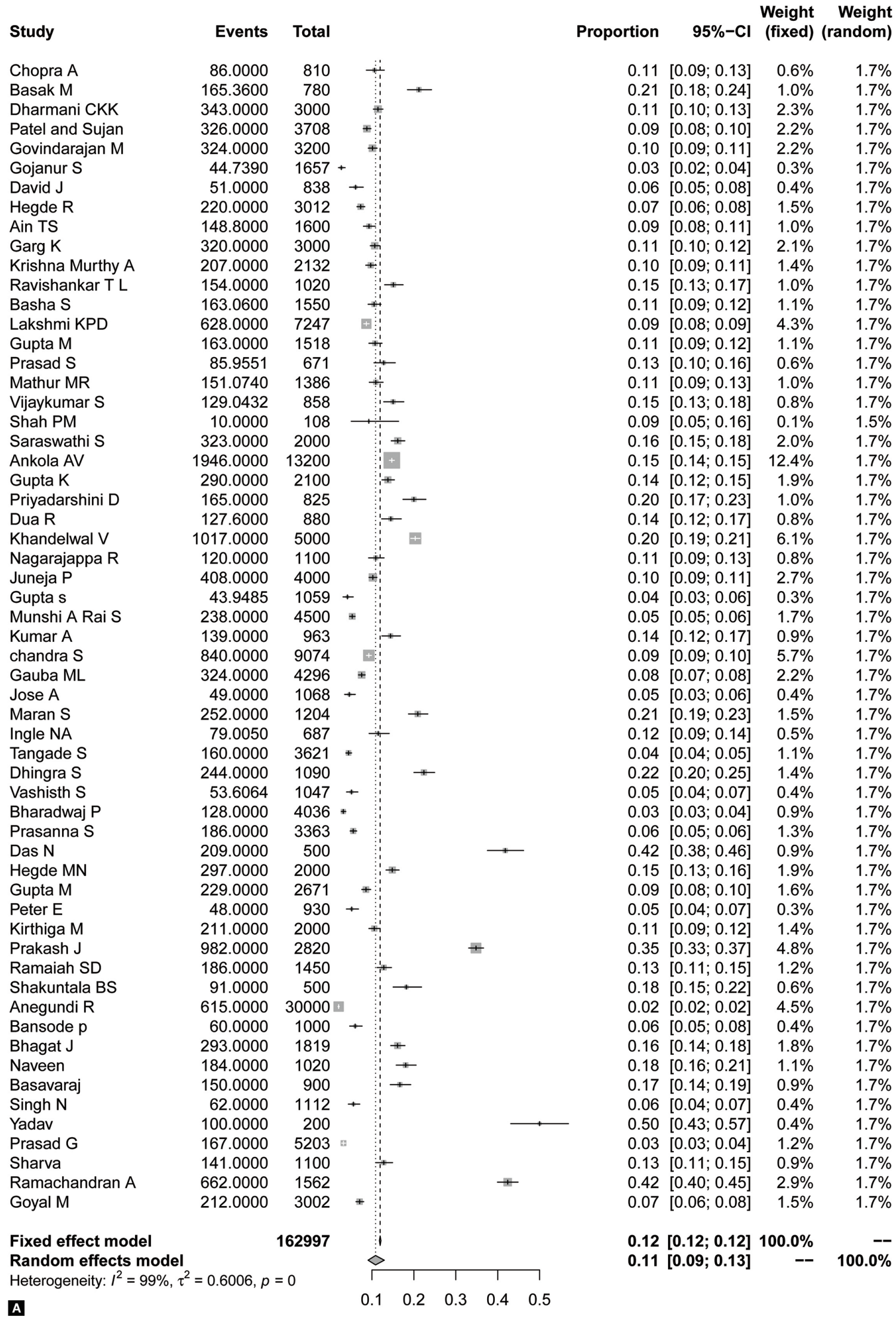




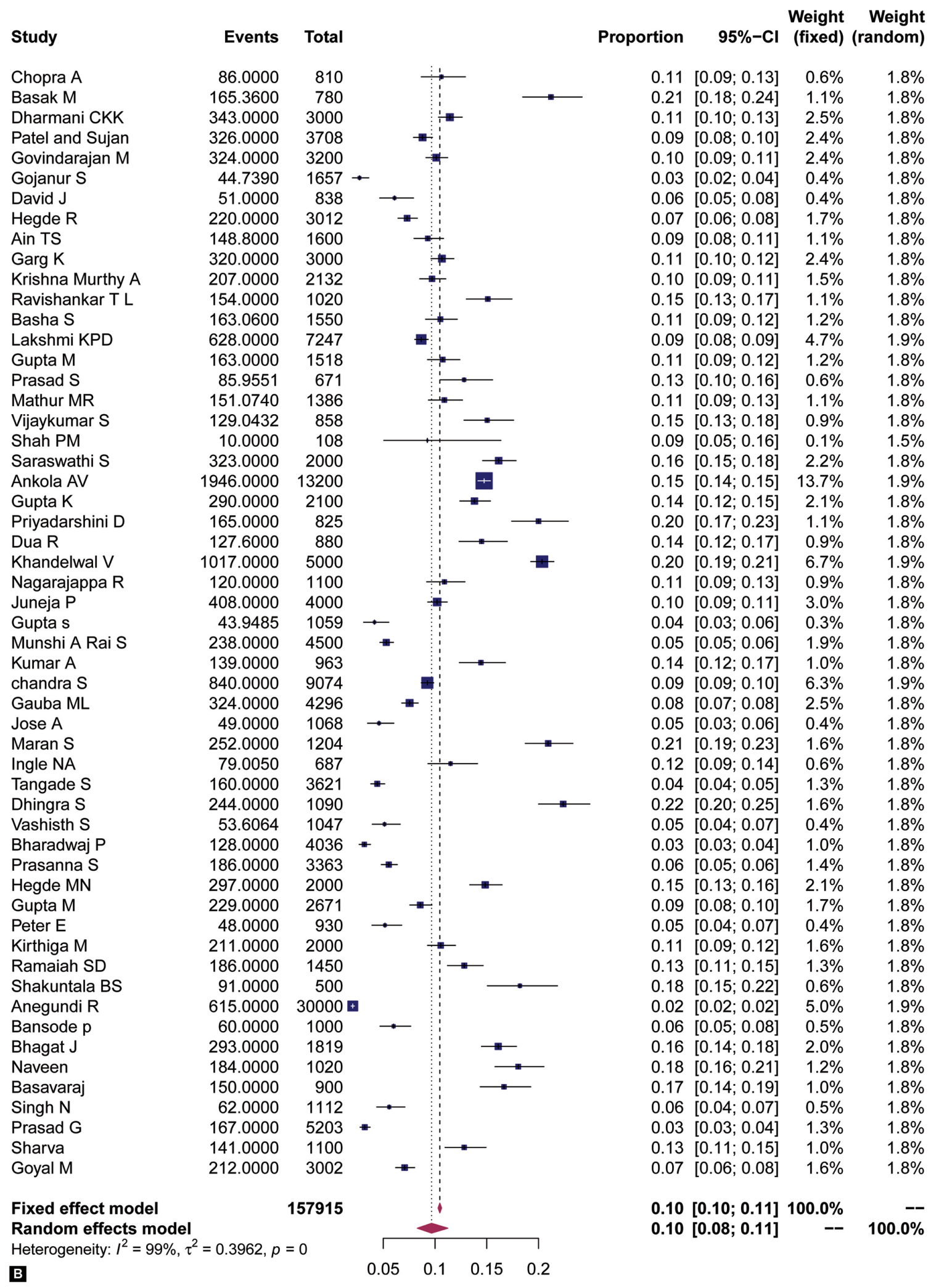

Figs 1A and B: (A) Forest plot of meta-analysis of studies in prevalence of traumatic dental injuries in permanent teeth (all studies included $n=59$ ). Study-specific and summary effect estimates $0.11(0.09-0.13)$ (heterogeneity $-l^{2}=99 \%$; Tau ${ }^{2}=0.6005 ; p<0.001$ ); (B) Forest plot for sensitivity analysis of meta-analysis of studies in prevalence of traumatic dental injuries in permanent teeth after excluding outliers studies (all studies included $n=55)$. Study-specific and summary effect estimates $0.10(0.08-0.11)$ (heterogeneity $-l^{2}=99 \% ; \operatorname{Tau}^{2}=0.3963 p<0.001$ ) 
Subgroup

Karnataka

Krishna Murthy A

Ravishankar T L

Basha S

Vijaykumar S

Ankola AV

Gupta K

Munshi A Rai S

Tangade S

Bharadwaj P

Prasanna S

Hegde MN

Kirthiga M

Ramaiah SD

Shakuntala BS

Random effects model

$I^{2}=99 \%[98 \% ; 99 \%], \chi_{13}^{2}=896.8(p<0.01)$

Non Karnataka

Chopra A

Basak M

Dharmani CKK

Patel and Sujan

Govindarajan M

Gojanur S

David J

Hegde R

Ain TS

Garg K

Lakshmi KPD

Gupta M

Prasad S

Mathur MR

Shah PM

Saraswathi S

Priyadarshini D

Dua R

Khandelwal V

Nagarajappa R

Juneja P

Gupta s

Kumar A

chandra S

Gauba ML

Jose A

Maran S

Ingle NA

Dhingra S

Vashisth $\mathrm{S}$

Das N

Gupta M

Peter E

Prakash J

Anegundi R

Bansode $p$

Bhagat J

Naveen

Basavaraj

Singh N

Yadav

Prasad G

Sharva

Ramachandran A

Goyal M

Random effects model

$I^{2}=99 \%[99 \% ; 99 \%], \chi_{44}^{2}=6854.34(p=0)$

Fixed effects (plural) model
$+$

$+$

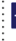

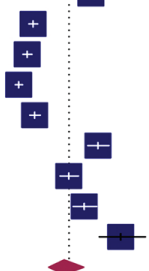

$$
\text { 01) }
$$

$\vdots$ 
Subgroup

Andreason

Patel and Sujan

Hegde R

Basha $S$

Random effects model
$l^{2}=86 \%[58 \% ; 95 \%], \chi_{2}^{2}=13.81(p<0.01)$

Clinical examination

Vijaykumar $\mathrm{S}$

Shah PM

Munshi A Rai S

Kumar A

chandra S

Gauba ML

Jose A

Bansode $p$

Yadav

Prasad G

Random effects model

$I^{2}=99 \%$ [99\%; 99\%], $x_{10}^{2}=1126.68(p<0.01)$

Ellis and Davies

Chopra A

Dharmani CKK

Govindarajan M

Gojanur S

Ain TS

Krishna Murthy A

Lakshmi KPD

Prasad S

Saraswathi S

Priyadarshini D

Dua R

Khandelwal V

Nagarajappa R

Juneja P

Gupta s

Ingle NA

Dhingra S

Vashisth $S$

Kirthiga $M$

Anegundi $\mathrm{R}$

Singh N

Goyal M

Random effects model

$1^{2}=99 \%[99 \% ; 99 \%], \chi_{21}^{2}=2830.24(p=0)$

O'Brien

David J

Mathur MR

Gupta K

Bharadwaj P

Random effects model
$I^{2}=99 \%[98 \% ; 99 \%], \chi_{3}^{2}=224.07(p<0.01)$

WHO

Basak M

Ravishankar T L

Ankola AV

Maran $S$

Tangade S

Prasanna $\mathrm{S}$

Hegde MN

Gupta M

Peter E

Prakash J

Ramaiah SD

Bhagat J

Naveen

Basavara

Sharva

Ramachandran A

$t^{2}=99 \%[99 \% ; 99 \%], \chi_{15}^{2}=2145.49(p=0)$

WHO and Andreason

Garg K

Shakuntala BS

Random effects model

$t^{2}=92 \%$ [79\%; 97\%], $x_{2}^{2}=24.4(p<0.01)$

Fixed effects (plural) model

$\gamma^{2}=99 \%$ [99\%; 99\%], $\chi_{5}^{2}=10.45(p=0.06)$
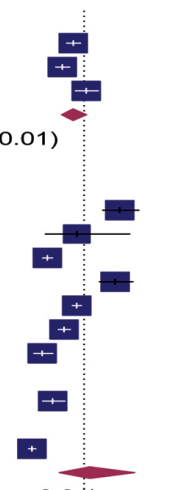

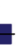

$+$

$\frac{+1}{+\frac{1}{+}}$

.
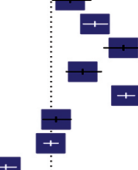

$+$
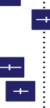

¿

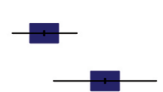

Proportion

$95 \%-\mathrm{CI}$

0.09 [0.08;0.10]

0.07 [0.06; 0.08]

$0.11[0.09 ; 0.12]$

0.15 [0.13;0.18]

$0.09[0.05 ; 0.16]$

0.05 [0.05;0.06]

0.14 [0.12;0.17]

0.09 [0.09;0.10]

0.08 [0.07;0.08]

$0.05[0.03 ; 0.06]$

0.42 [0.38;0.46]

0.06 [0.05;0.08]

$0.50[0.43 ; 0.57]$

0.53 [0.43; 0.57$]$

0.03 [0.03; 0.04$]$
0.11 [0.07; 0.17$]$

0.11 [0.09; 0.13]

0.11 [0.10;0.13]

0.10 [0.09;0.11]

0.03 [0.02;0.04]

0.09 [0.08; 0.11]

0.09 [0.08; 0.11$]$

0.10 [0.09; 0.11$]$

0.09 [0.08; 0.09$]$

0.13 [0.10;0.16]

0.16 [0.15; 0.18 ]

$0.20[0.17 ; 0.23]$

0.14 [0.12;0.17]

0.20 [0.19;0.21]

0.11 [0.09; 0.13]

0.10 [0.09;0.11]

0.104 [0.09;0.11]

$0.04[0.03 ; 0.06]$

0.12 [0.09; 0.14$]$

$0.22[0.20 ; 0.25]$

0.05 [0.04;0.07]

0.11 [0.09; 0.12]

0.02 [0.02; 0.02]

0.06 [0.04;0.07]

0.07 [0.06;0.08]

$0.09[0.07 ; 0.13]$

0.06 [0.05; 0.08]

0.11 [0.09; 0.13]

0.14 [0.12; 0.15]

$0.03[0.03 ; 0.04]$
$0.07[0.04 ; 0.15]$

0.21 [0.18;0.24]

$0.15[0.13 ; 0.17]$

$0.15[0.14 ; 0.15]$

$0.21[0.19 ; 0.23]$

0.04 [0.04;0.05]

0.06 [0.05; 0.06$]$

$0.15[0.13 ; 0.16]$

0.09 [0.08;0.10]

0.05 [0.04;0.07]

0.35 [0.33;0.37]

$0.13[0.11 ; 0.15]$

$0.13 ; 0.11 ; 0.15]$

$0.16[0.14,0.18]$

$0.18[0.16,0.21]$

0.17 [0.14;0.19]

0.13 [0.11;0.15]

$0.42[0.40 ; 0.45]$
$0.14[0.10 ; 0.19]$

$0.11[0.10 ; 0.12]$

$0.11[0.09 ; 0.12]$

$0.18[0.15 ; 0.22]$

0.13 [0.09; 0.17$]$

$0.10[0.09 ; 0.12]$

Figs 2A and B: (A) Forest plot for subgroup analysis of studies in Karnataka (14 studies included) and non-Karnataka state (45 studies included); (B) Forest plot for subgroup analysis of studies by classification criteria used for assessing TDI 
Table 5: Meta-regression of the study level covariates

\begin{tabular}{lccc}
\hline Study level covariate & $\beta$ coefficient & $R^{2}$ & $p$ value \\
\hline Sample size & -0.0001 & $18.15 \%$ & 0.0033 \\
Risk of bias & 0.0545 & $0.01 \%$ & 0.6906 \\
Year of publication & 0.0253 & $4.89 \%$ & 0.0534 \\
\hline
\end{tabular}

of 1.37-1.70. There are 1.52 times increased odds of experiencing traumatic dental injury among males as compared to females.

\section{Association between Inadequate Lip Coverage and TDI in Permanent Teeth}

Figure 3B depicts that the overall effect estimate of 17 studies was 4.76 (3.18-7.11), thus indicating that there are 4.76 times increased odds of experiencing traumatic dental injury among those with inadequate lip coverage as compared to those with adequate lip coverage.

\section{Association between Geographic Area and TDI in Permanent Teeth}

As explained in Figure 3C, the overall effect estimate of six studies was $1.30(0.88-1.91)$ indicating that there are 1.30 times increased odds of experiencing traumatic dental injury among those from the rural area as compared to those from the urban region. However, this finding was not statistically significant.

\section{Association between Increased Overjet of $>3.5 \mathrm{~mm},>5.5 \mathrm{~mm}$ with TDI in Permanent Teeth}

Figure 3D illustrates that the overall effect estimate from 13 studies was 4.84 (2.86-8.19), thus indicating that there are 4.84 times increased odds of experiencing traumatic dental injury among those with increased overjet $(>3.5 \mathrm{~mm}$ ) as compared to those with normal overjet. Figure $3 \mathrm{E}$ shows the overall effect estimate of nine studies as 4.93 (4.32-5.63), thus indicating that there are 4.84 times increased odds of experiencing traumatic dental injury among those with increased overjet $(>5.5 \mathrm{~mm}$ ) as compared to those with normal overjet.

\section{Trends}

\section{Trends in Prevalence of Dental Trauma in Permanent Teeth in India}

Figure 4A depicts the trends of prevalence for TDI in the percentage of the studies included over the years. The first study was conducted in 1967. Out of the 59 mentioned studies, the maximum number of prevalence studies $(n=32)$ has been done in the last 6 years. Figure 4B depicts the trend line of TDI prevalence in permanent teeth in India which denotes an upward trend. Figure 4C reveals the forecast of prevalence for TDI by average for the next 10 years that suggests an increasing pattern over the coming years. An estimate of the prevalence percentage for the corresponding year can be deduced. Figure 4D depicts the forecast of prevalence for TDI by average for the next 10 years broadly based on studies classified under the three most commonly used classifications that suggest a steeper pattern of TDI\% when using clinical examination compared to $\mathrm{WHO}^{75}$ and Ellis and Davies classification. ${ }^{76}$

\section{Assessment of Publication Bias}

The funnel plot (Fig. 5) for the current review is a simple scatter plot of the intervention effect estimates from individual studies against each study's precision (standard error) that is depicting considerable asymmetry with scattered studies depicting heterogeneity.

\section{Qualitative Synthesis of Other Factors in Which Meta- analysis Could Not Be Performed}

Out of 59 included studies, 50 studies $^{10-13,44-78,79}$ could provide data for causes of trauma. The most common cause mentioned was falls. ${ }^{10-13,19,22,24,25,27,31-36,43-47,49,51,54,55,58-64,66,69,73,74,77-79}$ Twentyfive $11,19,24,30,32,34,36,37,39,43,45,49,52,54,55,57,59,61-66,72,77$ studies provided information about the geographical place where the TDI occurred. The most common places mentioned were home ( 12 studies) ${ }^{11,24,36,}$ $43,49,52,54,57,63,64,66,72,77$ followed by the school (six studies). ${ }^{39,43,55,62,63,72}$ Eight studies ${ }^{13,24,43,49,57,62,66,69}$ evaluated socioeconomic status that was categorized to upper, middle, and lower socioeconomic status. Three studies ${ }^{13,57,72}$ mentioned that participant of middle socioeconomic status experienced greater TDI. In the other five studies, ${ }^{43,49,62,66,69}$ lower socioeconomic status groups experienced greater TDI. BMI was categorized as overweight/obese, normal, and underweight. There were four ${ }^{35,52,63,77}$ studies that could be included in this analysis. A greater prevalence of TDI in overweight or obese participants was reported in three studies. ${ }^{35,63,77}$ In one study, underweight participants were associated with TDI. ${ }^{52} \mathrm{~A}$ total of six studies ${ }^{48,49,51,57,59,63}$ assessed molar relations and all of them reported greater TDI prevalence among participants with class 2 molar relation. The affected tooth type was mentioned in $20^{13,23,24,31,32,36,43,47,48,51,56,58,59,62,64,66,77,80-82}$ studies. In 19 studies, maxillary central incisors were most commonly affected teeth. Out of the $24,711,13,22,24,30,31-33,35,37,43,45,47-49,51,55,57,63,66,78,81$ studies that reported the nature of the injury, enamel fracture was the most common findings in 18 studies. ${ }^{7,11,13,30,31,33,35,37,43,45,47-49,51,55,57,66}$

\section{Discussion}

The present systematic review was undertaken to evaluate the prevalence, trends, and associated factors of TDI in permanent teeth of children and adolescents in India. The overall prevalence of TDI from a total of 59 studies meeting the inclusion criteria in permanent teeth was $11 \%(0.11)(95 \% \mathrm{Cl} 0.09-0.13)$ with high heterogeneity among studies conducted in different geographic areas in India using the random effects model. A previous systematic review has reported $13 \%$ overall prevalence of TDI in India for 48 included studies. ${ }^{14}$ The difference may be due to inclusion of studies pertaining to primary dentition and high-risk groups such as athletes. The systematic reviews conducted in different countries reported a pooled prevalence of $18.6 \%{ }^{9}$ in Latin American and Caribbean countries and $17.5 \%{ }^{7}$ in Iran. This difference may be because of variation in the actual prevalence in the different study populations from different countries. By visual inspection, four outlier studies ${ }^{4,67,68,70}$ was noted indicating the varying prevalence of TDI in the studies conducted. Sensitivity analysis was done removing the outlier studies; however, no significant changes in the pooled result were observed.

There is a high degree of heterogeneity between studies, which can likely be explained by clinical, methodological, and statistical reasons. Although the study population included children and adolescents, factors that contributed to clinical heterogeneity include participants in the studies who differed in their age, gender, risk factors assessed, evaluation period, definition, and criteria used for TDI. There was considerable variability in the region where studies were conducted. Out of the 59 studies, 17 were done in 


\begin{tabular}{|c|c|c|c|c|c|c|c|c|c|c|c|}
\hline Study or Subgroup & \multicolumn{2}{|c|}{ Male } & \multicolumn{2}{|c|}{ Female } & Weight & $\begin{array}{c}\text { Odds Ratio } \\
\text { M-H, Random, } 95 \% \mathrm{Cl}\end{array}$ & \multicolumn{2}{|c|}{$\begin{array}{c}\text { Odds Ratio } \\
\text { M-H, Random, } 95 \% \mathrm{Cl}\end{array}$} & & & \\
\hline Ain TS & 39 & 767 & 35 & 833 & $2.2 \%$ & $1.22[0.77,1.95]$ & & & & E & \\
\hline Ankola AV & 1124 & 6512 & 822 & 6688 & $3.5 \%$ & $1.49[1.35,1.64]$ & & & & - & \\
\hline Basak M & 91 & 372 & 74 & 408 & $2.6 \%$ & $1.46[1.03,2.06]$ & & & & ए & \\
\hline Basha S & 88 & 798 & 75 & 752 & $2.7 \%$ & $1.12[0.81,1.55]$ & & & & - & \\
\hline Chopra A & 60 & 415 & 26 & 395 & $2.1 \%$ & $2.40[1.48,3.89]$ & & & & $\longrightarrow$ & \\
\hline Das $N$ & 130 & 296 & 79 & 204 & $2.6 \%$ & $1.24[0.86,1.78]$ & & & & † & \\
\hline David & 38 & 479 & 13 & 359 & $1.6 \%$ & $2.29[1.20,4.37]$ & & & & 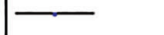 & \\
\hline Dharmamani CKK & 217 & 1500 & 126 & 1500 & $3.1 \%$ & $1.84[1.46,2.33]$ & & & & 一 & \\
\hline Dhingra S & 154 & 569 & 90 & 521 & $2.9 \%$ & $1.78[1.33,2.38]$ & & & & - & \\
\hline Dua R & 285 & 495 & 163 & 385 & $2.9 \%$ & $1.85[1.41,2.42]$ & & & & - & \\
\hline Garg K & 201 & 1683 & 119 & 1317 & $3.1 \%$ & $1.37[1.07,1.73]$ & & & & - & \\
\hline Gojanur S & 29 & 935 & 16 & 696 & $1.7 \%$ & $1.36[0.73,2.52]$ & & & & 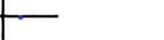 & \\
\hline Govindarajan M & 202 & 1890 & 122 & 1310 & $3.1 \%$ & $1.17[0.92,1.48]$ & & & & t & \\
\hline Gupta m & 158 & 1520 & 71 & 1151 & $2.9 \%$ & $1.76[1.32,2.36]$ & & & & - & \\
\hline Gupta M & 115 & 871 & 48 & 647 & $2.6 \%$ & $1.90[1.33,2.70]$ & & & & - & \\
\hline Gupta S & 29 & 573 & 15 & 485 & $1.6 \%$ & $1.67[0.88,3.15]$ & & & & & \\
\hline Jose A & 34 & 490 & 15 & 570 & $1.7 \%$ & $2.76[1.48,5.13]$ & & & & - & \\
\hline Juneja $P$ & 279 & 2058 & 129 & 1534 & $3.1 \%$ & $1.71[1.37,2.13]$ & & & & $\rightarrow$ & \\
\hline Khandelwal V & 686 & 2907 & 331 & 2093 & $3.4 \%$ & $1.64[1.42,1.90]$ & & & & $\rightarrow$ & \\
\hline Krishnamurthy & 132 & 1074 & 75 & 1058 & $2.8 \%$ & $1.84[1.36,2.47]$ & & & & $\sim$ & \\
\hline Krithiga M & 143 & 1173 & 68 & 827 & $2.8 \%$ & $1.55[1.14,2.10]$ & & & & - & \\
\hline Laxmi KPD & 490 & 4527 & 138 & 2720 & $3.2 \%$ & $2.27[1.87,2.76]$ & & & & - & \\
\hline Maran S & 144 & 697 & 108 & 507 & $2.9 \%$ & $0.96[0.73,1.27]$ & & & & & \\
\hline Mathur MR & 93 & 736 & 55 & 650 & $2.6 \%$ & $1.56[1.10,2.22]$ & & & & - & \\
\hline Nagarajappa R & 66 & 572 & 54 & 528 & $2.5 \%$ & $1.14[0.78,1.68]$ & & & & $\leftarrow$ & \\
\hline Naveen & 121 & 515 & 63 & 505 & $2.7 \%$ & $2.15[1.54,3.01]$ & & & & - & \\
\hline Patel \& Sujan & 183 & 1867 & 143 & 1841 & $3.1 \%$ & $1.29[1.03,1.62]$ & & & & - & \\
\hline Peter E & 22 & 366 & 26 & 564 & $1.8 \%$ & $1.32[0.74,2.37]$ & & & & - & \\
\hline Prakash J & 540 & 1551 & 442 & 1269 & $3.4 \%$ & $1.00[0.86,1.17]$ & & & & & \\
\hline Prasad G & 102 & 2464 & 65 & 2739 & $2.8 \%$ & $1.78[1.30,2.44]$ & & & & - & \\
\hline Priyadarshini D & 112 & 462 & 53 & 363 & $2.6 \%$ & $1.87[1.30,2.68]$ & & & & $\longrightarrow$ & \\
\hline Ramaiah SD & 118 & 800 & 68 & 650 & $2.8 \%$ & $1.48[1.08,2.04]$ & & & & - & \\
\hline Ravishankar TL & 97 & 519 & 57 & 501 & $2.6 \%$ & $1.79[1.26,2.55]$ & & & & - & \\
\hline Shava & 110 & 538 & 31 & 562 & $2.4 \%$ & $4.40[2.90,6.69]$ & & & & & \\
\hline Tangade S & 120 & 2418 & 40 & 1203 & $2.6 \%$ & $1.52[1.05,2.19]$ & & & & - & \\
\hline Vashisth S & 353 & 726 & 216 & 315 & $2.9 \%$ & $0.43[0.33,0.57]$ & & & 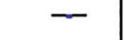 & & \\
\hline Vijaykumar S & 74 & 452 & 55 & 406 & $2.5 \%$ & $1.25[0.86,1.82]$ & & & & - & \\
\hline Yadav & 60 & 120 & 40 & 80 & $1.8 \%$ & $1.00[0.57,1.76]$ & & & & - & \\
\hline Total $(95 \% \mathrm{Cl})$ & & 46707 & & 39136 & $100.0 \%$ & $1.52[1.37,1.70]$ & & & & $\downarrow$ & \\
\hline Total events & 7039 & & 4166 & & & & & & & & \\
\hline $\begin{array}{l}\text { Heterogeneity. Tauz } \\
\text { Test for overall effec }\end{array}$ & $\begin{array}{l}0.09 ; \mathrm{Ch} \\
\mathrm{Z}=7.58\end{array}$ & $\begin{array}{l}=202.4 \\
0<0.00\end{array}$ & $\begin{array}{l}\text { 48, } d f=3 \\
1001)\end{array}$ & $3(P \propto 0$. & 00001); 1 & $=82 \%$ & 0.01 & 0.1 & Female & 10 & 100 \\
\hline
\end{tabular}

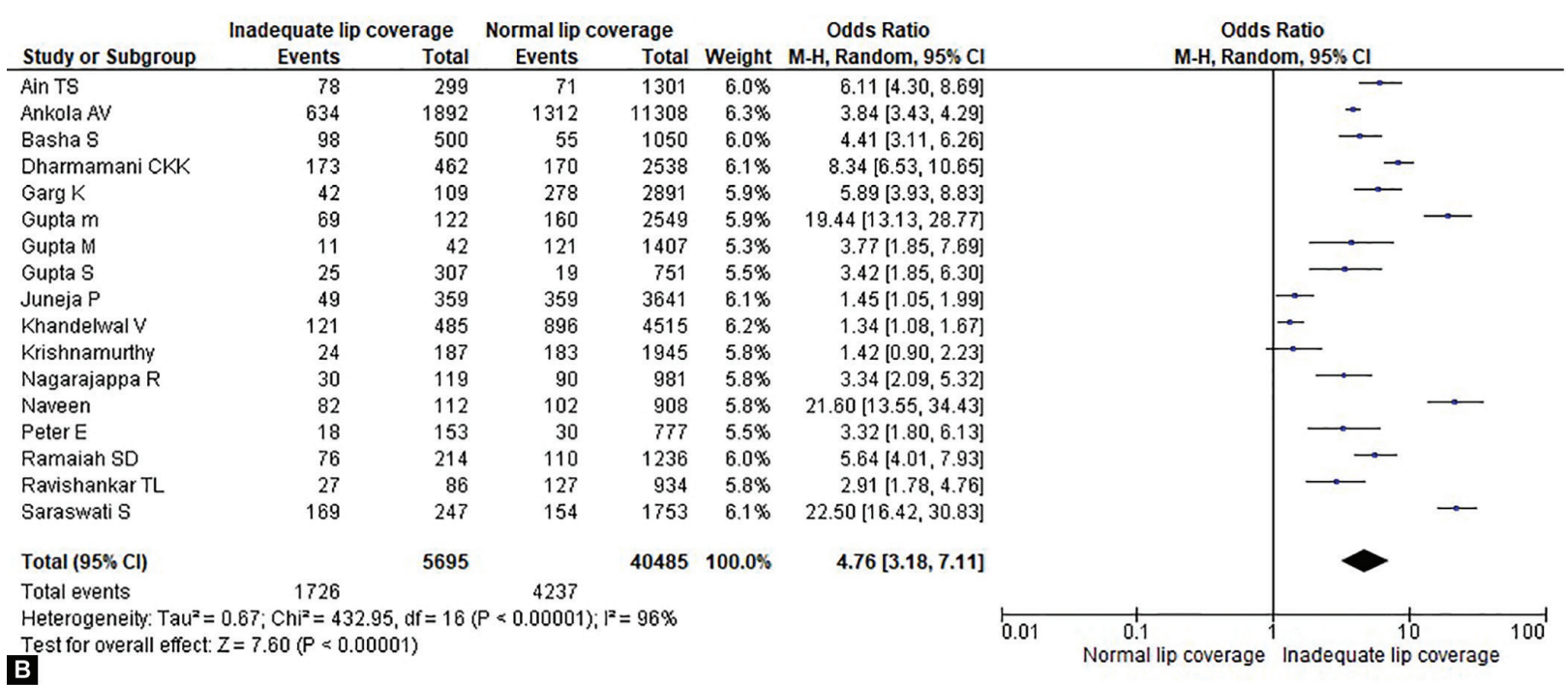



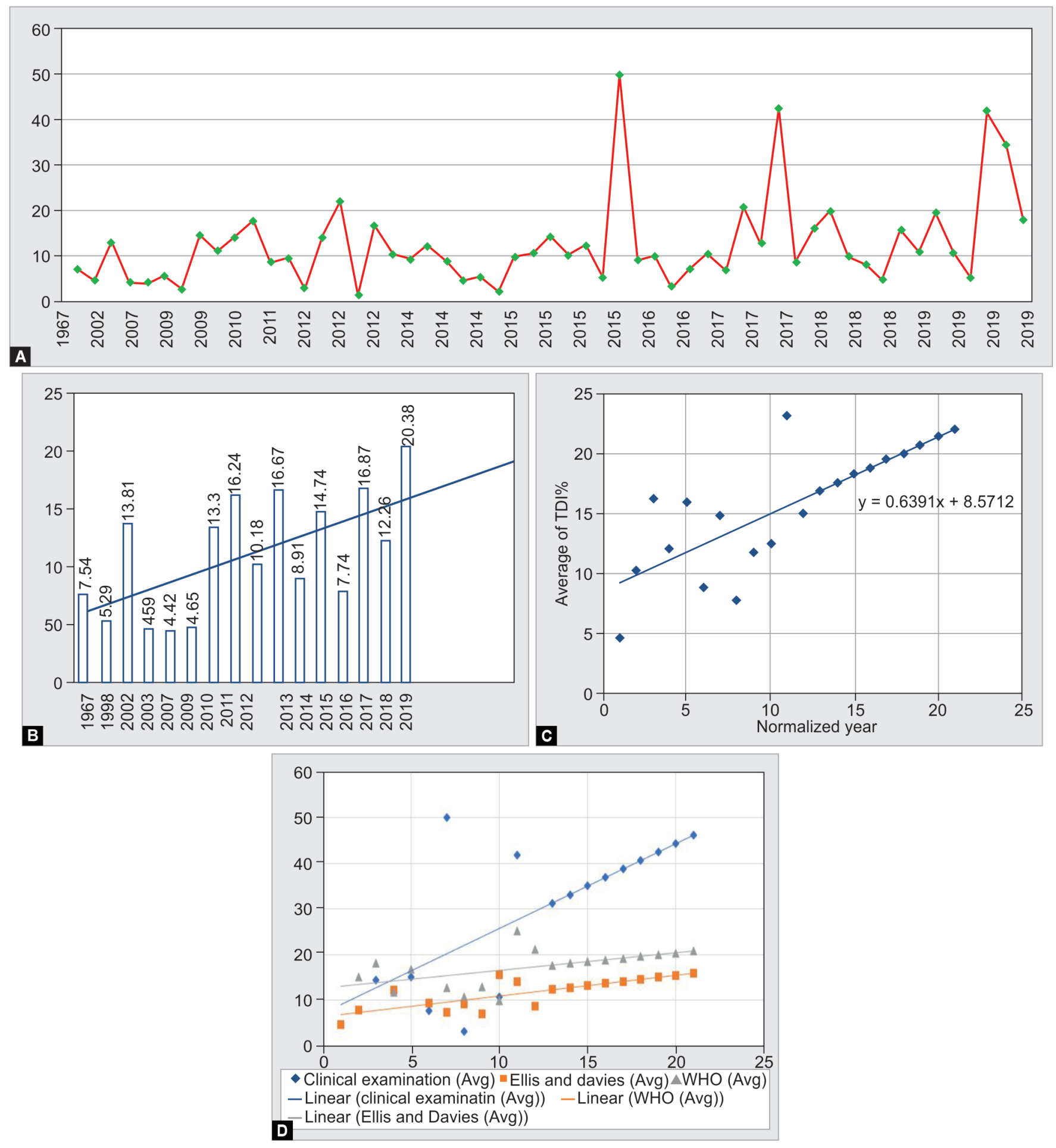

Figs 4A to D: (A) Trends in prevalence of TDI in permanent teeth $(n=59)$; (B) Trend line of TDI prevalence in permanent teeth by reported average for each year; (C) Forecast of prevalence of TDI in permanent teeth by average for next 10 years; (D) Forecast of prevalence of TDI in permanent teeth by average for next 10 years based on classification

the Southern state of Karnataka. Hence, a subgroup analysis was performed based on Karnataka and non-Karnataka studies. The moderator effect was not statistically significant as there were a varying number of studies in each group. No subgroup analysis was able to explain the heterogeneity.
The commonly used criteria were WHO classification. ${ }^{75}$ The WHO classification of oral trauma describes injuries to the internal structures of the mouth. Luxation injuries are grouped as one and not divided into intrusive, extrusive, and lateral luxation. Injuries to the alveolar socket and fractures of the mandible or maxilla are not 


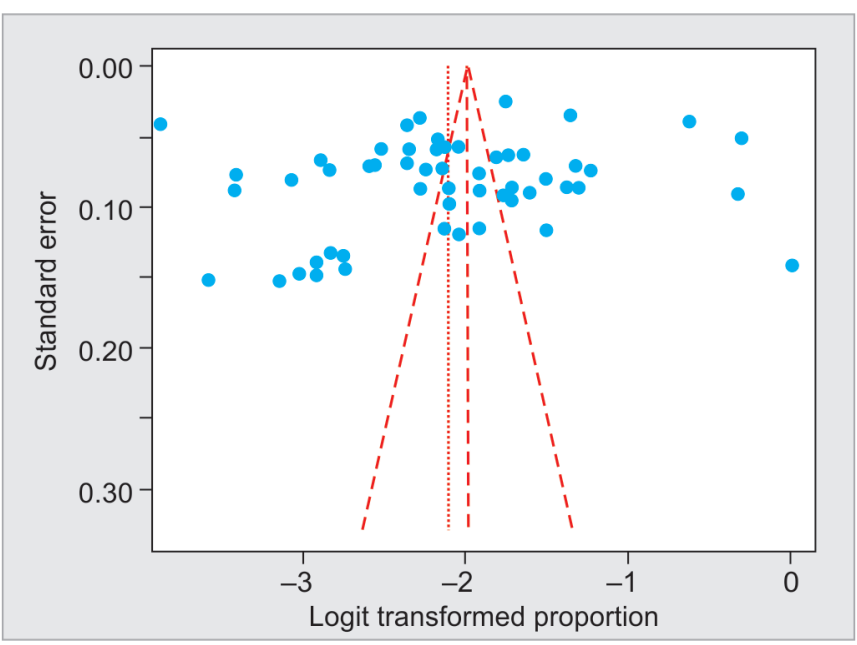

Fig. 5: Funnel plot for pooled prevalence of TDI in permanent teeth

grouped under oral injuries, but rather are classified separately as fractures of facial bones.

The Ellis classification ${ }^{76}$ is a modification of the WHO system which has been used most commonly by various authors for recording dental trauma. This system is a simplified classification which groups many injuries and allows for subjective interpretation by including broad terms such as "simple" or "extensive" fractures. However, injuries to the alveolar socket and fractures of the mandible and maxilla have not been classified here, which can underestimate the actual prevalence percentage. Unlike the WHO classification, Andreasens ${ }^{80}$ is a more comprehensive system having 19 groups including injuries to the teeth, supporting structures, gingiva, and oral mucosa that allows for minimal subjective interpretations. Nevertheless, this is the least commonly used criterion in Indian studies. Although the best option to evaluate TDI could not be narrowed down, a universal classification can be used to facilitate further comparisons between survey results. Subgroup analysis based on classification used could not prove heterogeneity statistically.

Methodologically the included studies varied in the sampling technique, sample size, and geographic location. Qualitative appraisal of the studies revealed that 42 studies reported sampling method and only 22 studies reported the evaluation period and sample size calculation. The sample size included in the meta-analysis ranged from $108^{56}$ to $30,000 .^{33}$ There were also differences in the quality of the studies with the majority of them having moderate-to-high risk of bias. Both methodological and clinical sources of heterogeneity contribute to the occurrence and magnitude of statistical heterogeneity. ${ }^{81}$

When gender was assessed as a risk factor for TDI, boys were reported to have about two times greater odds of TDI compared to girls (OR $=1.52 ; 95 \% \mathrm{Cl}: 1.37-1.70)$. This finding was compatible with reports from similar systematic reviews in other countries like the Latin America and Caribbean countries ${ }^{9}$ and Iran. ${ }^{7}$ A possible explanation for this finding might be due to boys engaging more actively in sports, fights, and outdoor activities than girls.

The meta-analysis from the forest plot could not deduce a significant association of the rural population with $T D I(O R=1.30$; $95 \% \mathrm{Cl}: 0.88-1.91)$. A possible explanation could be that only six studies had assessed this variable. Individuals raised in rural areas are exposed to considerably different environmental risk factors than those living in urban regions such as household and school setting, play area, and lifestyle behaviors, which have all been implicated as potential environmental risk factors for TDI. ${ }^{57}$

The studies that evaluated socioeconomic status reported the greatest prevalence of TDI among adolescents in lower socioeconomic status. Meta-analysis could not be conducted because the data was not extractable. This was in contrast to a systematic review which proved that the scientific evidence indicates no association between socioeconomic indicators and TDI. ${ }^{82}$ Socioeconomic differences in the prevalence of TDI in adolescents are likely due to differential exposure to environmental factors of the neighborhood, parental education level and employment status, and the level of social capital in the community. ${ }^{13,43}$ This difference could be partly explained by the fact that there is no single measure of socioeconomic status, and the studies for the systematic review did not include observations from the Indian population. The standardization of a measure, particularly in the Indian scenario which is a lower-middle-income country, is needed for the acquisition of scientific evidence of such an association.

The association between obesity and the occurrence of TDI in the present systematic review was doubtful. Although results suggest that there was an increased chance of TDI among overweight/obese individuals, ${ }^{35,63,77}$ inconsistencies exist among the four studies ${ }^{35,52,63,77}$ reported. In a systematic review by Gottems et al., ${ }^{10}$ the evidence favors no significant association between dental trauma and physical activity and nutritional status. However, the authors were inconclusive of the results due to the relatively low level of current evidence especially because of obesity. Consequently, prospective cohort studies are needed to address this issue further.

The current systematic review indicates that fall injuries were most commonly associated with dental trauma followed by sports and collision. This was a common finding in other reviews as well., ${ }^{7,8}$ Besides the present systematic review also suggested that TDI most frequently occurs at home than in school, street, or playgrounds. Previous studies with similar findings suggested that this could be because the children and adolescents spend more time at home and the parents are unaware of preventing TDI. 2,6,7,11

In the present review, overjet was classified as studies reporting an overjet of $>3.5 \mathrm{~mm}(\mathrm{OR}=4.84 ; 95 \% \mathrm{Cl}: 2.86-8.19)$ and $>5.5 \mathrm{~mm}$ (OR $=4.84 ; 95 \% \mathrm{Cl}: 4.32-5.63)$. In both cases, a positive association of as much as five times greater with TDI than normal overjet was found in the meta-analysis. An Australian systematic review conducted by Arraj $^{82}$ reported that an increased overjet was significantly associated with higher odds of developing trauma in all dentition stages and age-groups. A similar study by Soriano EP in Brazil also suggested that an overjet size greater than $5 \mathrm{~mm}$ and inadequate lip coverage were predisposing factors related to the occurrence of traumatic dental injuries. ${ }^{83}$ Increased overjet due to the proclination of anterior teeth leaves them vulnerable and less protected by lips. Thus, when the lips do not cover the entire tooth, they do not absorb any impact and all force is applied to the tooth.

The present review showed that participants with inadequate lip coverage were three times as likely to be associated with TDI compared to those without TDI (OR $=4.76 ; 95 \% \mathrm{Cl}: 3.18-7.11)$. The finding was in accordance with other systematic reviews as well. ${ }^{7-9,12}$ Even before orthodontic treatment is started, such patients should be periodically monitored and educated about TDI prevention. The use of mouthguards should also be promoted in these groups. ${ }^{2}$ 
In addition, increased association of Angle's class 2 malocclusion (particularly division 1 molar relation) with TDI is inferred from the qualitative synthesis. It has been well documented that malocclusion is associated with less masticatory efficiency and a poorer quality of life. As such, clinical factors of malocclusion associated with a higher chance of suffering TDI (such as greater overjet, inadequate lip sealing, class II division I molar relation) should be prevented and treated not only because of their association with TDI but also due to their impact on children and adolescents. ${ }^{8}$

Based on the qualitative synthesis of the studies, maxillary central incisors account for most of the TDI followed by maxillary lateral incisors, which was in agreement with other studies. ${ }^{2,7}$ This could be partly explained by the fact that the anterior teeth are more prone to injures due to their obvious placement in the arch and also maxillary central incisors are positioned to receive the maximum impact during a fall or collision. The nature of injury involved maximum enamel fracture followed by enamel and dentine fractures. This finding was supported by other review articles as well. ${ }^{6,7,11}$

There is noticeable fluctuation in the trends of TDI prevalence over the years. An increasing pattern for trend line with a positive slope can be observed suggesting that TDI could pose a significant dental public health issue in permanent dentition. In addition to the trend line, a forecast plot for the next 10 years based on different classifications used was generated to further understand the variation in the prevalence of TDI. All the three most commonly used classification indicated an increasing pattern with a positive slope. A steep gradient was observed in the case of TDI classified by mere clinical examination and a considerably moderate rise in the case of Ellis and Davies and WHO criteria. A possible explanation for the overestimation of TDI by clinical examination could be inability to follow a specific set of standard criteria. Inconsistencies of outcome assessment by different examiners can thus add more to the reason why the observations were more scattered resulting in a steep forecast line. As for Ellis and Davies and WHO criteria, most of the observations were almost in line with the forecast trend suggesting a proper estimation for TDI. Nevertheless, it is worth to state that this trend analysis does not reflect exact data from all regions of India. Further studies should be conducted to map possible different scenarios nationwide considering different geographic locations for more prediction.

Considerable asymmetry was observed in the funnel plot for the present systematic review. This may be due to several reasons, including true heterogeneity (i.e., smaller studies differ from larger ones in terms of the study population, exposure levels of risk factors, etc.), selection bias and bias in design or analysis, or chance.

There were several limitations in this systematic review. It should be noted that the data for Indian studies are weighted toward Southern and Northern India with only 1 of the 59 studies reporting data from West Bengal. Therefore, the data presented should be interpreted as pertaining mainly to some regions of India. Moreover, the literature search was restricted to studies published in permanent teeth, which may have introduced bias into the study. However, there were only a few studies that were excluded for this reason. Meta-analysis could not be performed for several predictors as data were not extractable for each study level covariate. Subgroup analysis could not be relied upon because of the high disparity in the number of studies under each subgroup. Varying criteria for assessing TDI as well as lack of longitudinal studies could have underestimated the actual prevalence.
Despite these limitations, this systematic review provides a comprehensive overview of prevalence, associated risk factors of TDI across time and geography compared to other published review in India without any language restriction in the included studies. The burden of TDI varies by geography and appears to be increasing over time. Definitive reasons for the increasing incidence rates of TDI are largely unknown and may be attributed to a greater number of studies being conducted in the last 5 years. Despite several Indian surveys conducted for TDI in the literature, the present systematic review highlights the need for incidence and prevalence data in many regions of India, particularly from the Eastern and North Eastern and Western regions. Future studies in these regions are required for additional insight into the geographic patterns and time trends of TDI that will provide important perceptions into the etiology and may well serve as a foundation for the formulation of an objective universal classification for TDI that would facilitate judging the actual prevalence.

\section{Public Health Significance and Recommendation}

This review will help researchers estimate the public health burden of TDI and assist policymakers in the allocation of appropriate healthcare resources and research in specific geographic regions. Simple measures such as identifying high-risk groups and prompting them for orthodontic treatment can curb the incidence of TDI. Parents, teachers, and supervisors must be educated particularly about the potential risk factors of TDI and safeguarding home by padding sharp furniture or corners, carpeting the play area or hall so that the children can be careful at home when left unattended. Further, they must be made aware of consequences of deleterious oral habits, such as chewing on hard objects like pencils or pens that can be preventable. Children and adolescents, especially males, should be informed about risk-taking behavior and to watch out for possible obstruction while playing so that they do not trip down. Also, they must be advised to practice safe and responsible playing without pushing or knocking each other with heavy objects. Maintenance of certain harmonized movement measures in the school classrooms, corridors, or staircases where the children are more likely to get injured due to collision and falls can prevent sudden impact injuries to the teeth. The play area of the schools should be preferably covered with grass and children involved in sports activities should be informed about using mouthguards. Therefore, the results of this study should be considered in the adoption of public health policies and inform further research to the same end preferably with a universal classification for assessing TDI.

\section{Conclusion}

The present systematic review reported that the prevalence of dental trauma in permanent teeth among children and adolescents in India was $11 \%(0.11)(95 \% \mathrm{Cl} 0.09-0.13)$, with a high degree of heterogeneity among studies. Most of the studies presented a moderate-high risk of bias. Male gender, increased overjet, and inadequate lip coverage were observed to be significantly associated with TDI. Also, a qualitative synthesis revealed a positive association of sociodemographic factors, such as rural population, low socioeconomic status, and environmental factors, like place of occurrence and cause of TDI, with TDI. However, the data could not be pooled under the criteria required for meta-analysis. Trends for TDI seem to be increasing with years among children and 
adolescent population in India. To advance the understanding of the key determinants of TDI, future population-based analytical studies should focus on reporting the incidence and/or prevalence of TDI among marginalized communities.

\section{ACKnowledgment}

Author would like to thank Dr Ankit Chandra (Senior Resident, Centre for Community Medicine, AlIMS, New Delhi) for retrieving articles from EMBASE, Dr. Naga Naveena N (Post graduate trainee, Dept. of Oral and Maxillofacial Pathology, SCBDCH, Odisha) for her continuous support and Mr. Shriram Muthuswamy (Lead Data Analyst, SUBEX, Bengaluru) for providing me with all the technical and statistical assistance through every phase of this research.

\section{References}

1. Petti $S$, Glendor $U$, Andersson L. World traumatic dental injury prevalence and incidence, a meta-analysis-One billion living people have had traumatic dental injuries. Dent Traumatol 2018;34(2):71-86. DOI: 10.1111/edt.12389.

2. Glendor U. Epidemiology of traumatic dental injuries - a 12 year review of the literature. Dent Traumatol 2008;24(6):603-611. DOI: 10.1111/j.1600-9657.2008.00696.x.

3. Gojanur S, Yeluri R, Munshi AK. Prevalence and etiology of traumatic injuries to the anterior teeth among 5 to 8 years old school children in Mathura City, India: an epidemiological study. Int J Clin Pediatr Dent 2015;8(3):172-175. DOI: 10.5005/jp-journals-10005-1308.

4. Yadav N, Saxena V, Jain M, et al. Liaison amid problem behavior and traumatic dental injury among children aged 12-15 years in Bhopal. J Indian Assoc Public Heal Dent 2015;13(3):234-238. DOI: 10.4103/23195932.165217.

5. Lopez D, Waidyatillake N, Zaror C, et al. Impact of uncomplicated traumatic dental injuries on the quality of life of children and adolescents: a systematic review and meta-analysis. BMC Oral Health 2019;19(1):1-12. DOI: 10.1186/s12903-019-0916-0.

6. Lam R. Epidemiology and outcomes of traumatic dental injuries: a review of the literature. Aust Dent J 2016;61(Suppl. 1):4-20. DOl: 10.1111/adj.12395.

7. Azami-Aghdash S, Ebadifard Azar F, Pournaghi Azar F, et al. Prevalence, etiology, and types of dental trauma in children and adolescents: systematic review and meta-analysis. Med J Islam Repub Iran 2015;29(1):591-596. PMCID: PMC4715389.

8. Magno MB, Nadelman P, Leite KL de F, et al. Associations and risk factors for dental trauma: a systematic review of systematic reviews. Community Dent Oral Epidemiol 2020;48(6):447-463. DOI: 10.1111/ cdoe.12574.

9. Aldrigui JM, Jabbar NS, Bonecker M, et al. Trends and associated factors in prevalence of dental trauma in Latin America and Caribbean: a systematic review and meta-analysis. Community Dent Oral Epidemiol 2014;42(1):30-42. DOI: 10.1111/cdoe.12053.

10. Goettems ML, Schuch HS, Hallal PC, et al. Nutritional status and physical activity level as risk factor for traumatic dental injuries occurrence: a systematic review. Dent Traumatol 2014;30(4):251-258. DOI: 10.1111/edt.12102.

11. Bastone EB, Freer TJ, McNamara JR. Epidemiology of dental trauma: a review of the literature. Aust Dent J 2000;45(1):2-9. DOI: 10.1111/j.18347819.2000.tb00234.x.

12. Corrêa-Faria P, Martins CC, Bönecker $M$, et al. Clinical factors and socio-demographic characteristics associated with dental trauma in children: a systematic review and meta-analysis. Dent Traumatol 2016;32(5):367-78. DOI: 10.1111/edt.12268.

13. Mathur MR, Watt RG, Millett CJ, et al. Determinants of socioeconomic inequalities in traumatic dental injuries among Urban Indian adolescents. PLoS One 2015;10(10):1-12. DOI: 10.1371/journal. pone.0140860.
14. Tewari N, Mathur VP, Siddiqui I, et al. Prevalence of traumatic dental injuries in India: a systematic review and meta-analysis. Indian J Dent Res 2020;31(4):601-614. DOI: 10.4103/ijdr.IJDR_953_19.

15. Wang WW, Yang ZR, Zhou QX, et al. Introduction to COSMOS-E: Guidance on conducting systematic reviews and Meta-analyses on etiology of observational studies. Zhonghua Liu Xing Bing Xue Za Zhi 2020;41(12):2149-2159. DOI: 10.3760/cma.j.cn112338-20191024-00758.

16. Shamliyan T, Kane RL, Dickinson S. A systematic review of tools used to assess the quality of observational studies that examine incidence or prevalence and risk factors for diseases. J Clin Epidemiol 2010;63(10):1061-1070. DOI: 10.1016/j.jclinepi.2010.04.014.

17. Gauba ML. A correlation of fractured anterior teeth to their proclination. J Indian Dent Assoc 1976;39(8):105-112. PMID: 5236649.

18. Rai SB, Munshi AK. Traumatic injuries to the anterior teeth among South Kanara school children - a prevalence study. J Indian Soc Pedod Prev Dent 1998;16(2):44-51. PMID: 11813754.

19. Gupta K, Tandon S, Prabhu D. Traumatic injuries to the incisors in children of South Kanara District. A prevalence study. J Indian Soc Pedod Prev Dent 2002;20(3):107-113. PMID: 12435009.

20. Jose A, Joseph MR. Prevalence of dental health problems among school going children in rural Kerala. J Indian Soc Pedod Prev Dent 2003;21(4):147-151. PMID: 14765615.

21. Tangade PS. The prevalence of anterior teeth fracture and its relation to malocclusion in 12 and 15 year old school children Belgaum city India. J Oral Heal Community Dent 2007;1(1):7-11. DOI: 10.5005/ johcd-1-1-7.

22. David J, Åstrøm AN, Wang NJ. Factors associated with traumatic dental injuries among 12-year-old schoolchildren in South India. Dent Traumatol 2009;25(5):500-505. DOI: 10.1111/j.1600-9657.2009.00807.x.

23. Bharadwaj P. Traumatic injuries of anterior teeth: a prevalent study in school children of coorg district [dissertation]: Rajiv Gandhi University of Health Sciences; 2009.

24. Ravishankar TL, Kumar MA, Nagarajappa R, et al. Prevalence of traumatic dental injuries to permanent incisors among 12-year-old school children in Davangere, South India. Chin J Dent Res 2010;13(1):57-60. PMID: 20936193.

25. Gupta S, Kumar-Jindal S, Bansal M, et al. Prevalence of traumatic dental injuries and role of incisal overjet and inadequate lip coverage as risk factors among 4-15 years old government school children in Baddi-Barotiwala area, Himachal Pradesh, India. Med Oral Patol Oral Cir Bucal 2011;16(7):1-6. DOI: 10.4317/medoral.17265.

26. Ingle NA, Baratam N, Charania Z. Prevalence and factors associated with traumatic dental injuries (TDI) to anterior teeth of 11-13 year old school going children of Maduravoyal, Chennai. J Oral Health Community Dent 2010;4:55-60.

27. Kumar A, Bansal V, Veeresha KL SG. Prevalence of traumatic dental injuries among 12- to 15-year-old schoolchildren in Ambala district, Haryana, India. Oral Heal Prev Dent 2011;9(3):301-305. PMID: 22068187.

28. Naveen VK, Ramesh N, Reddy VVK. Prevalence of traumatic dental injuries to permanent incisors among 12 years old school children in Tandoor, Andhra Pradesh. J Indian Assoc Public Health Dent 2011;9(6):704-707. ISSN: 2319-5932

29. Patel MC, Sujan SG. The prevalence of traumatic dental injuries to permanent anterior teeth and its relation with predisposing risk factors among 8-13 years school children of Vadodara city: an epidemiological study. J Indian Soc Pedod Prev Dent 2012;30(2):151157. DOI: 10.4103/0970-4388.99992.

30. Govindarajan M, Reddy V, Ramalingam K, et al. Prevalence of traumatic dental injuries to the anterior teeth among three to thirteen-year-old school children of Tamilnadu. Contemp Clin Dent 2012;3(2):164. DOI: 10.4103/0976-237X.96819.

31. Ankola AV, Hebbal M, Sharma R, et al. Traumatic dental injuries in primary school children of South India - a report from districtwide oral health survey. Dent Traumatol 2013;29(2):134-138. DOI: 10.1111/j.1600-9657.2012.01139.x. 
32. Sharma S, Dua R. Prevalence, causes, and correlates of traumatic dental injuries among seven-to-twelve-year-old school children in Dera Bassi. Contemp Clin Dent 2012;3(1):38. DOI: 10.4103/0976-237X.94544.

33. Rajesh A, Vijay T, Raksha B. Traumatic injuries to anterior teeth in school children of Southern. IJDE 2012;5(2):71-79.

34. Dhingra S, Marya CM, Avinash J, et al. Prevalence and risk factors associated with trauma to permanent anterior teeth in 12 to 15 year old school going children in urban and rural areas of Faridabad, Haryana: a comparative study. Int J Prev Clin Dent Res 2012;8(2): 89-95.

35. Vijaykumar S, Guna Shekhar M, Vijayakumar R. Traumatic dental injuries and its relation to overweight among Indian school children living in an urban area. J Clin Diagnostic Res 2013;7(11):2631-2633. DOI: 10.7860/JCDR/2013/7528.3633.

36. Basavaraj P, Sunil MK, Nagarajappa R, et al. Correlation between oral health and child-oidp index in 12- and 15-year-old children from Modinagar, India. Asia-Pacific J Public Heal 2014;26(4):390-400. DOI: 10.1177/1010539513510553.

37. Chopra A, Lakhanpal M, Rao N, et al. Traumatic dental injuries among twelve to fifteen years old school children in Panchkula. Arch Trauma Res 2014;3(1):1-5. DOI: 10.5812/atr.18127.

38. Bansode P, Deshpande S, Ahire C, et al. Dental caries occurrence, types and occurrence of trauma to anterior teeth, their severity in relation to pulpal involvement in patients visiting O. P. D. of Govt. Dental College and Hospital, Aurangabad. J Evol Med Dent Sci 2014;3(44):10924-10929. DOI: 10.14260/jemds/2014/3427.

39. Murthy AK, Mallaiah P, Sanga R. Prevalence and associated factors of traumatic dental injuries among 5- to 16-year-old schoolchildren in Bengaluru City, India. Oral Heal Prev Dent 2014;12(1):37-43. DOI: 10.3290/j.ohpd.a31226.

40. Prasad S, Tandon S, Pahuja M, et al. Prevalence of traumatic dental injuries among school going children in Farukhnagar, District Gurgaon. Int J Sci Study 2014;2:44-49. ISBN: 0815131003 9780815131007.

41. Chandra SS. Traumatic injuries to permanent anterior teeth among Indians: frequency, aetiology and risk factors. ENDO 2014;8(1): 23-30.

42. Patel P, Puwar T, Shah N, et al. Improving adolescent health: learnings from an interventional study in Gujarat, India. Indian J Community Med 2018;43(5):S12-S17. DOI: 10.4103/ijcm.IJCM_286_18.

43. Basha S, Mohammad RN, Swamy HS, et al. Association between traumatic dental injury, obesity, and socioeconomic status in 6-and 13-year-old schoolchildren. Soc Work Public Health 2015;30(4):336344. DOI: 10.1080/19371918.2014.1002598.

44. Hegde M, Sajnani A. Prevalence of permanent anterior tooth fracture due to trauma in South Indian population. Eur J Gen Dent 2015;4(2):87. DOI: 10.4103/2278-9626.154183.

45. Kirthiga M, Praveen R, Umesh W. Severity of dental trauma and its associated factors in 11-16 years old school children in Davangere city, India. J Orofac Scime 2015;7(2):95-99. DOI: 10.4103/0975-8844.169755.

46. Ramaiah SD, Maraiah PK. Prevalence of Traumatic Dental Injuries among Blind School Children in South Karnataka. IOSR J Dent Med Sci 2014;13(11):18-22. DOI: 10.9790/0853-131151822.

47. Singh N, Singh A, Jolly MS. Prevalence of traumatic dental injuries in school going children of Lucknow, India. Int J Oral Health Med Res 2015;2(2):39-42. ISSN 2395-7387.

48. Ain TS, Telgi RL, Sultan S, et al. Prevalence of traumatic dental injuries to anterior teeth of 12-year-old school children in Kashmir, India. Arch Trauma Res 2016;5(1):1-8. DOI: 10.5812/atr.24596.

49. Gupta M, Kumar S, Kaur J, et al. Prevalence, risk factors, and treatment needs of traumatic dental injuries of anterior teeth among 11-15 year old children attending government and private schools of Bhopal City, India. J Adv Oral Res 2016;7(2):32-39. DOI: 10.1177/2229411220160206.

50. Prasad MG, Radhakrishna AN, Kambalimath HV, et al. Oral health status and treatment needs among 10126 school children in West Godavari district, Andhra Pradesh, India. J Int Soc Prevent Community Dent 2016;6(3):213-218. DOI: 10.4103/2231-0762.183102.
51. Hegde R, Agrawal G. Prevalence of traumatic dental injuries to the permanent anterior teeth among 9- to 14-year-old schoolchildren of Navi Mumbai (KhargharBelapur Region), India. Int J Clin Pediatr Dent 2017;10(2):177-182. DOI: 10.5005/jp-journals-10005-1430.

52. Garg K, Kalra N, Tyagi R, et al. An Appraisal of the prevalence and attributes of traumatic dental injuries in the permanent anterior teeth among 7-14-year-old school children of North East Delhi. Contemp Clin Dent 2017;8(2):218-224. DOI: 10.4103/ccd.ccd_133_17.

53. Corrêa-Faria P, Martins CC, Bönecker M, et al. Absence of an association between socioeconomic indicators and traumatic dental injury: a systematic review and meta-analysis. Dent Traumatol 2015;31(4):255-266. DOI: 10.1111/edt.12178.

54. Shashikiran N, Ahirwar P, Maran P, et al. Prevalence of Dental Caries and Traumatic Dental Injuries among 6- to 12-year-old Children in Bhopal City, India. Int J Clin Pediatr Dent 2017;10(2):172-176. DOI: 10.5005/jp-journals-10005-1429.

55. Sharva V, Reddy V, Bhambal A, et al. Traumatic dental injuries to the anterior teeth among 12-year and 15-year-old schoolchildren of urban and rural areas of Bhopal District, Central India: a prevalence study. CHRISMED J Heal Res 2017;4(1):38. DOI: 10.4103/2348-3334.196065.

56. Shah PM, Jeevanandan G. Prevalence of common dental diseases in 6-15-year-old children visiting Saveetha Dental College and Hospitals. Drug Invent Today 2018;10(1):2756-2760. ISSN: 0975-7619.

57. Khandelwal V, Nayak UA, Nayak PA, et al. Prevalence of traumatic injuries to the anterior teeth among 3-17-year-old school children of Indore and correlating it with Kuppuswamy SES, occlusal relationship and ascertaining percentage of those seeking the treatment. Int $J$ Adolesc Med Health 2018;33(1):3-12. DOI: 10.1515/ijamh-2018-0061.

58. Saraswathi S, Kumar Rathinavelu P. Prevalence of permanent anterior teeth trauma in children between 8-12 years in urban and rural districts in Rohtak, Haryana, India. Biomed Pharmacol J 2018;11(1):469-475. DOI: 10.13005/bpj/1396.

59. Juneja P, Kulkarni S, Raje S. Prevalence of traumatic dental injuries and their relation with predisposing factors among 8-15 years old school children of Indore City, India. Clujul Med 2018;91(3):328-335. DOI: 10.15386/cjmed-898.

60. Bhagat V, Singh EP. Esthetic ignorance: the prevalence of traumatized anterior teeth among adolescents in Ghaziabad District, Uttar Pradesh, India. Int Healthc Res J 2018;2(8):199-204. DOI: 10.26440/ ihrj.v2i8.165.

61. Gupta M, Upadhyaya P, Parihar AS, et al. Prevalence, risk factors, and treatment needs of traumatic dental injuries to anterior teeth among 6-15-year-old children. Int J Curr Med Pharm Res 2018;4(2):2958-2963. DOI: 10.24327/23956429.ijcmpr20180376.

62. Peter E, Narayan V. Prevalence of traumatic dental injuries to maxillary anterior teeth, associated risk factors and its influence on quality of life among adolescents in Kerala. Int J Dent Health Sci 2018; 5(4):512-520.

63. Dharmani CKK, Pathak A, Sidhu HS. Prevalence of traumatic dental injuries to anterior teeth in 8-12-year-old schoolchildren of Patiala City, Punjab, India: an epidemiological study. Int J Clin Pediatr Dent 2019;12(1):25-29. DOI: 10.5005/jp-journals-10005-1583.

64. Priyadarshini D, Ravindran S, Solomon N, et al. Prevalence of treatment dental injuries in children between 11- and 13-years old Ayanavaram, Chennai, India. Paripex Indian J Res 2019;8(4):13-14. ISSN No 2250-1991.

65. Vashisth S, Bansal M, Gupta N. Prevalence of traumatic injuries and knowledge regarding emergency care among 11-14 years government school children in rural area, Dehra, Kangra District, Himachal Pradesh. Oral Health Dent Mgmt 2014;13(3):666-668. PMID: 25284533.

66. Nagarajappa R, Ramesh G, Uthappa R, et al. Risk factors and patterns of traumatic dental injuries among Indian adolescents. J Dent Sci 2020;15(1):96-103. DOI: 10.1016/j.jds.2019.07.003.

67. Das M, Reddy LV, Singh S. Prevalence of traumatic dental injuries among 5-16-year-old children and knowledge of teachers in the management of traumatic dental injuries. J Indian Assoc Public Health Dent 2019;17(4):328-332. DOI: 10.4103/jiaphd.jiaphd_185_18. 
68. Prakash J, Kumari S. Prevalence of traumatic dental injuries of anterior tooth with associated risk factors in children in Patna. Int J Med Res 2019;5:239-245. ISSN: 2454-9142.

69. Shakuntala BS, Kalpavriksha A. Prevalence of traumatic dental injuries among residential school children and day scholars of 9-14 years in South Bengaluru. Int J Sci Res Publ 2019;9(8):p9245. DOI: 10.29322/ IJSRP.9.08.2019.p9245.

70. Ramachandran A, Khan S, Baskaradoss J. Epidemiology of traumatic dental injuries among adults in an Indian sub-population. Open Access Emerg Med 2021;13:201-206. DOI: 10.21203/rs.2.12327/v1.

71. Basak M, Biswas $R$, Bhattacherjee $S$, et al. Prevalence and pattern of childhood injuries in Siliguri City, West Bengal, India. Indian J Public Health 2020;64(1):39-43. DOI: 10.4103/ijph.IJPH_401_18.

72. Lakshmi KP, Narayanan MB, Kumar SG, et al. Permanent anterior teeth fractures and its impact on oral health-related quality of life among 8-15-year-old school children of Chennai city - a crosssectional survey. Int J Appl Basic Med Res 2020;10(1):30-36. DOI: 10.4103/ijabmr. IJABMR_346_18.

73. Goyal N, Singh S, Mathur A, et al. Traumatic dental injuries prevalence and their impact on self-esteem among adolescents in India: a comparative study. J Clin Diagnostic Res 2017;11(8):ZC106-ZC110. DOI: 10.7860/JCDR/2017/27496.10510.

74. Prasanna S, Giriraju A, Jyothi C. Relationship of traumatic dental injuries to the permanent anterior teeth in relation to occlusal relationship among 7-14 years old school children - a cross sectional survey. Int J Contemp Med Res 2019;6(5):E19-E24. DOI: 10.21276/ijcmr.2019.6.5.33.

75. Bezroukov V. The application of the International Classification of Diseases to dentistry and stomatology. Community Dent Oral Epidemiol 1979;7(1):21-24. DOI: 10.1111/j.1600-0528.1979.tb01180.x.
76. Ellis RG. The classification and treatment of injuries to the teeth of children; a reference manual for the dental student and the general practitioner. 5th ed. Chicago: Year Book Medical Publishers; 1970. p. 56-199.

77. Basha S, Mohammad RN, Swamy HS. Incidence of dental trauma among obese adolescents - a 3-year-prospective study. Dent Traumatol 2015;31(2):125-129. DOI: 10.1111/edt.12137.

78. Vashishtha V, Gupta R, Basavaraj P, et al. Effectiveness of health education intervention among the school teachers regarding management of traumatic dental injury in Modinagar. J Indian Assoc Public Heal Dent 2016;14(1):17. DOI: 10.4103/2319-5932.178729.

79. Rambharos RR, Kalaskar AR, Wankhade RM, Mehta JD. Evaluation of prevalence, etiological and risk factors of traumatic dental injury in 12-14 years old school going children of Central India. SRM J Res Dent Sci 2014;5:73-77. DOI: 10.4103/0976-433X.132074.

80. Andreasen J. Etiology and pathogenesis of traumatic dental injuries. Scand Dent J/Eur J Oral Sci 1970;78(4):329-342. DOI: 10.1111/j.16000722.1970.tb02080.x.

81. Gagnier JJ, Moher D, Boon $\mathrm{H}$, et al. Investigating clinical heterogeneity in systematic reviews: a methodologic review of guidance in the literature. BMC Med Res Methodol 2012;12(1):111. DOI: 10.1186/14712288-12-111.

82. Arraj GP, Rossi-Fedele G, Doğramacı EJ. The association of overjet size and traumatic dental injuries - a systematic review and meta-analysis. Dent Traumatol 2019;35(4-5):217-232. DOI: 10.1111/edt.12481.

83. Soriano EP, Caldas AF, Angeiras Góes PS. Risk factors related to traumatic dental injuries in Brazilian schoolchildren. Dent Traumatol 2004;20(5):246-250. DOI: 10.1111/j.1600-9657.2004.00246.x. 